\title{
COMMERCIALIZATION OF ACADEMIC RESEARCH IN CANADIAN UNIVERSITIES: OPTIMIZING TECHNOLOGY TRANSFER
}

by

Melissa Golberg, Bachelor of Commerce, Ryerson University, 2015

A thesis presented to Ryerson University in partial fulfilment of the requirements in the program of Master of Science in Management

Toronto, Ontario, Canada, 2018

(C) Melissa Golberg, 2018 


\section{Author's Declaration}

\section{AUTHOR'S DECLARATION FOR ELECTRONIC SUBMISSION OF A THESIS}

I hereby declare that I am the sole author of this thesis. This is a true copy of the thesis, including any required final revisions, as accepted by my examiners.

I authorize Ryerson University to lend this thesis to other institutions or individuals for the purpose of scholarly research.

I further authorize Ryerson University to reproduce this thesis by photocopying or by other means, in total or in part, at the request of other institutions or individuals for the purpose of scholarly research.

I understand that my thesis may be made electronically available to the public. 
Commercialization of Academic Research in Canadian Universities: Optimizing Technology Transfer Melissa Golberg, 2018 Master of Science in Management

Ryerson University

\section{Abstract}

In recent years, in addition to the basic tenets of teaching and research, commercialization and innovation have become core priorities in higher education (Friedman \& Silberman, 2003; Etzkowitz, 2003; Rasmussen et al., 2006). Universities have the right ingredients to be natural technology transfer incubators with a high influx of innovators and the capability to create new ventures and have high potential to generate a high level of economic development.

Commercialization allows the results of innovative research to be utilized through transformation into marketable products or 'technology transfer'. Since the 1980s, Canadian universities have begun dedicating resources and effort to discover how to best harness the innovation arising out of university-based research for knowledge transfer and revenue generation through commercialization. This thesis focuses on specific university inputs that influence the volume of technology transferred to industry through various commercialization channels and the impact each factor may have considering the institution size. Through data verified primarily from the Association of University Technology Managers’ (AUTM) annual surveys of Canadian and American universities from 2011 to 2015, this study analyzes the effect of administrative characteristics on technology transfer at a university. While the results of the study do not provide much conclusive guidance on the reasons behind growth in university-industry technology transfer, they do suggest that there is some greater effect in large universities that leads to more technology transfer activity than in smaller universities. 


\section{Acknowledgements}

I would like to thank my thesis supervisor, Dr. Murtaza Haider, for taking the time to guide me through my research and helping me make sense of my results as well as Dr. Sari Graben who got me started on my graduate research journey and provided me with tools required to begin my

research. I would also like to thank Dr. Hong Yu for her patience and encouragement throughout the process and both Dr. Yu and Dr. Alan Kaplan for their time and feedback as members of my examination committee. Thank you to the ARC team in The Office of the Vice-President, Research and Innovation. Lastly, I would like to thank Dr. Greg Singer whose encouragement and support allowed me to pursue my MScM degree. 


\section{Table of Contents}

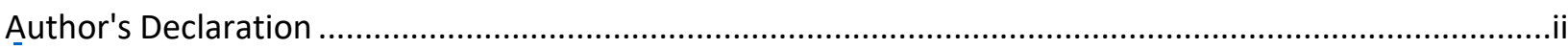

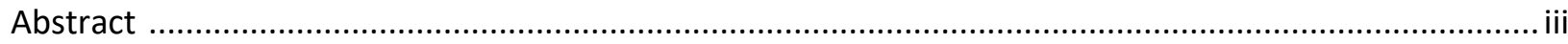

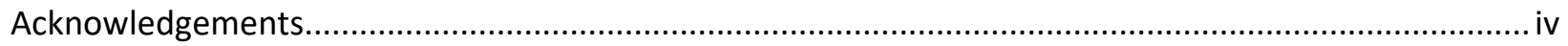

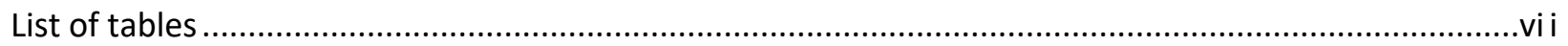

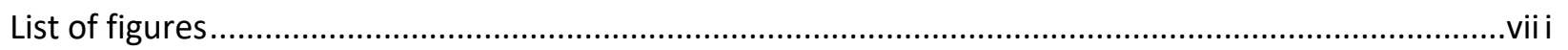

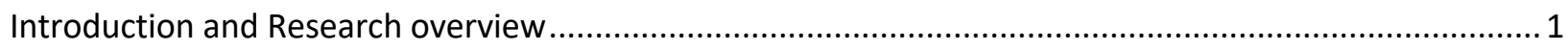

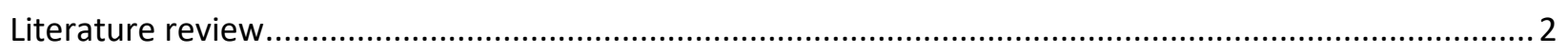

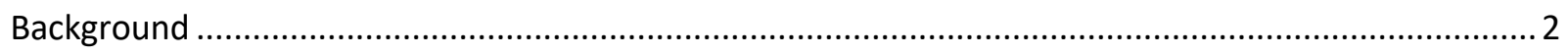

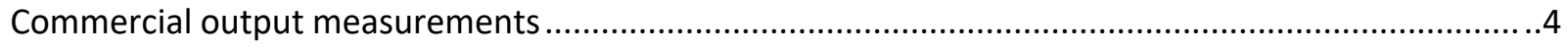

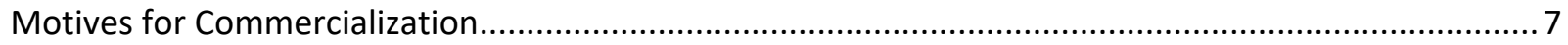

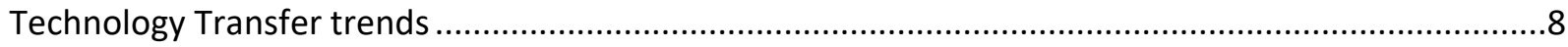

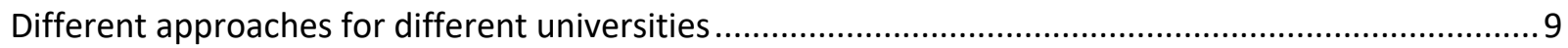

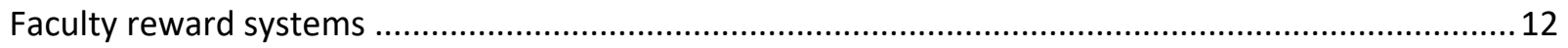

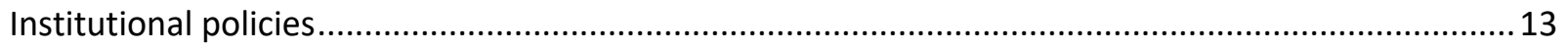

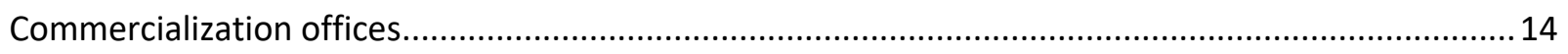

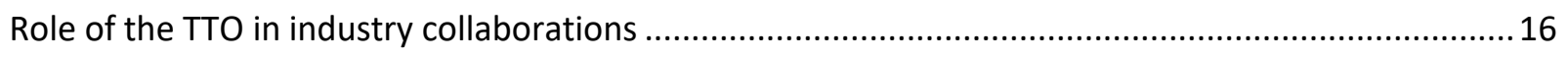

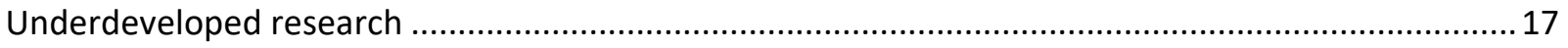

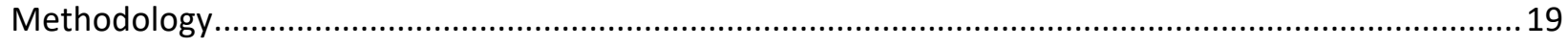

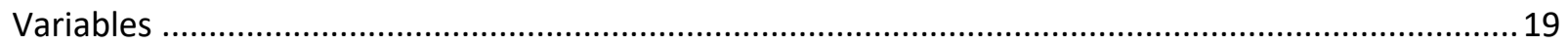

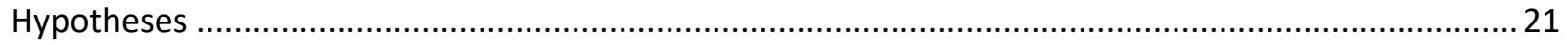

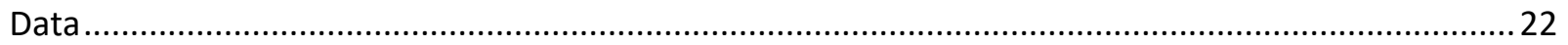

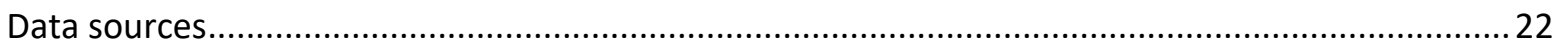

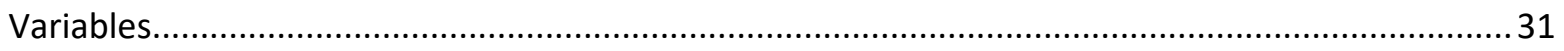

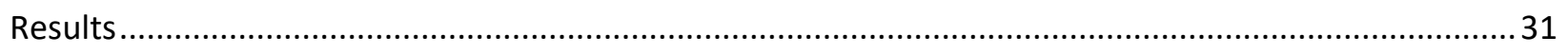

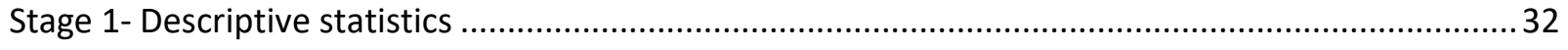

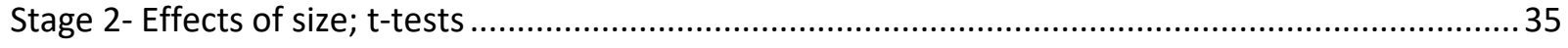

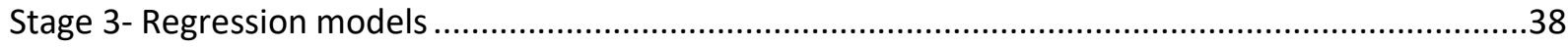

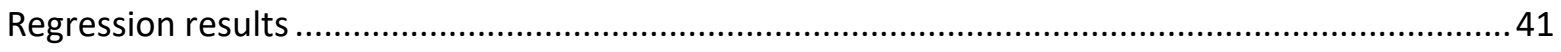

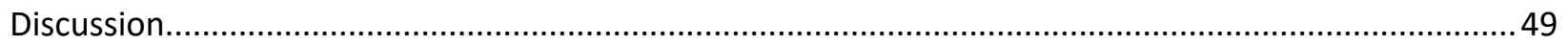

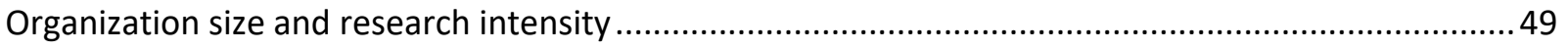

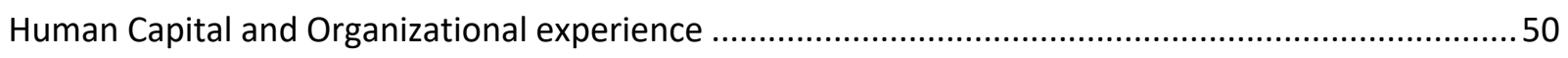

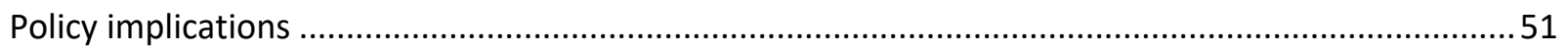




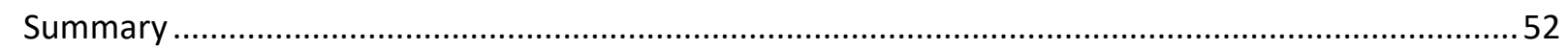

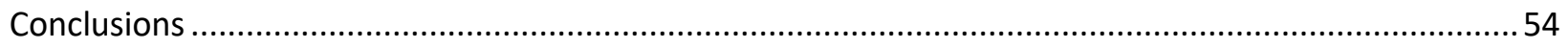

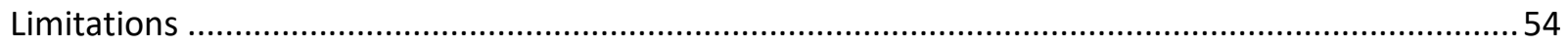

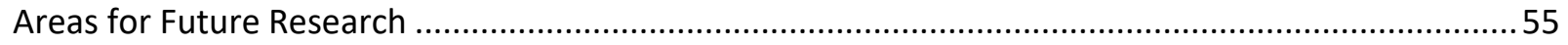

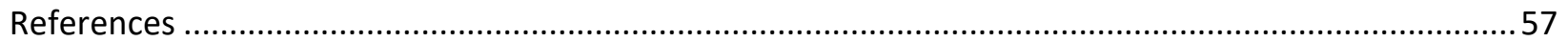


List of Tables

\begin{tabular}{|l|l|}
\hline Table & Page \\
\hline 1 & 7 \\
\hline 2 & 7 \\
\hline 3 & 20 \\
\hline 4 & 21 \\
\hline 5 & 29 \\
\hline 6 & 29 \\
\hline 7 & 31 \\
\hline 8 & 32 \\
\hline 9 & 32 \\
\hline 10 & 35 \\
\hline 11 & 37 \\
\hline 12 & 41 \\
\hline 13 & 42 \\
\hline 14 & 42 \\
\hline 15 & 42 \\
\hline 16 & 42 \\
\hline & \\
\hline
\end{tabular}


List of Figures

\begin{tabular}{|l|l|}
\hline Table & Page \\
\hline 1 & 4 \\
\hline 2 & 4 \\
\hline 3 & 23 \\
\hline 4 & 33 \\
\hline 5 & 39 \\
\hline 6 & 39 \\
\hline 7 & 39 \\
\hline 8 & 39 \\
\hline 9 & 39 \\
\hline 10 & 39 \\
\hline 11 & 40 \\
\hline 12 & 40 \\
\hline 13 & 40 \\
\hline
\end{tabular}




\section{Introduction and Research overview}

In recent years, in addition to the basic tenets of teaching and research, commercialization and innovation has become a core priority in higher education (Friedman \& Silberman, 2003;

Etzkowitz, 2003; Rasmussen et al., 2006). Universities have the right ingredients to be natural technology transfer incubators with a high influx of innovators and the capability to create new ventures and have high potential to generate a high level of economic development.

Commercialization allows the results of innovative research to be utilized through transformation into marketable products or 'technology transfer'. Since the 1980s, Canadian universities have dedicated resources and effort to best harness the innovation arising out of university-based research for knowledge transfer and revenue generation through commercialization.

This thesis study seeks to identify the ability of a university to gain influence over the volume of academic innovation commercialized and answer the question of 'what university characteristics impact the amount of commercialization activity generated'? University-Industry Technology Transfer (UITT) is the key measure of commercialization used in this study of academic innovation in a Canadian context. This study also explores the impact that size, measured as annual research revenue, has on the ability of a university to alter the amount of technology transferred. Technology Transfer Offices (TTO) to report on a large number of key variables through various annual surveys that serve as the core of the data set for this study. 


\section{Literature review}

\section{Background}

Initiatives geared towards increasing the rate of technology transfer to the private sector are plentiful, the benefits of which will boost the economy in the long term by stimulating employment and productivity (Friedman and Silberman, 2003) and help move innovation off the shelf and into the hands of those that can benefit from it. There are critics, however, such as Geuna \& Nesta (2006) that are not convinced of the benefits of localized commercialization approaches, explaining that while the patenting activity is growing, most (European) universities are not able to reap profit through licensing since such initiatives only help future revenues which are undetermined and unpredictable.

The Association of Public and Land-grant Universities (APLU) released a report of the results from a commission on Innovation, Competitiveness, and Economic Prosperity. The report listed four guidelines that universities should target to evolve their UITT activities, 2 of which are significant: 1) UITT should be measured: in contributions to economic prosperity, not revenue; and 2) resource allocation such as staffing must be taken into account (APLU, 2017)

Five such contributions to economic prosperity are licenses, royalties, patents, sponsored research, and licensing agreements. Using regression analysis, (Thursby et al., 2001) found that universities were capable of maximizing efficiency of each of these commercial processes. Thursby and Kemp (2002), however, conducted a review and synthesis of literature on institutions engaged in UITT and concluded that universities are often inefficient at taking full advantage of the technology available to them. The overall growth of commercialization is from growth from all universities rather than efforts to catch up from the inefficient ones. The 
efficiency of 57 universities was known from six years of survey results. A Data Envelopment Analysis (DEA) indicated that efficiency was increasing. Universities, however, were still far from achieving their potential output. The increase in the efficiency only reflects the increase in commercialization efforts by all universities over time (Anderson et al., 2007; Chapple et al., 2005; Sohn and Moon, 2004; Thursby and Kemp, 2002).

Siegel et al. (2004) expanded on an outdated assumption that technology transfer is a linear process, beginning with a discovery by a university researchers, flowing through the university and ending with a firm as is depicted in Figure 1. Their expansion seen in Figure 2 detailed a new paradigm in which acknowledged the role that incentives play faculty's initiative to commercialize their findings. Cummings (2013) and Etzkowitz (2004) came to a similar conclusion, criticizing this linear model for technology transfer and citing the need for change from a model focused solely on the licensing mechanism of commercialization. This updated model reflects a level of collinearity amongst UITT outputs. 


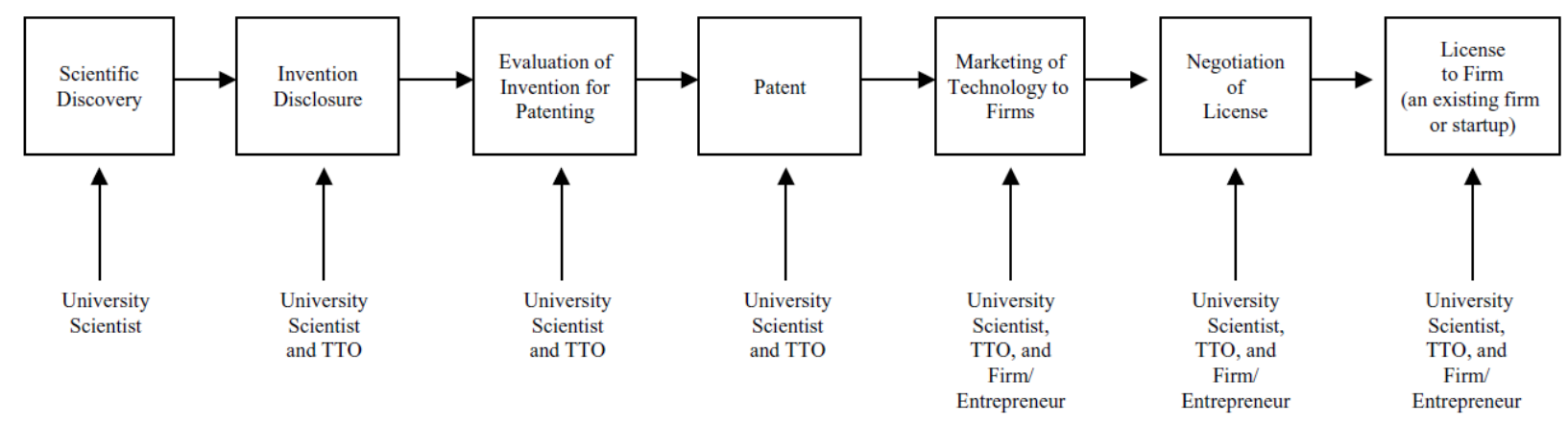

Figure $1 \quad$ Siegel et al. (2004), page119

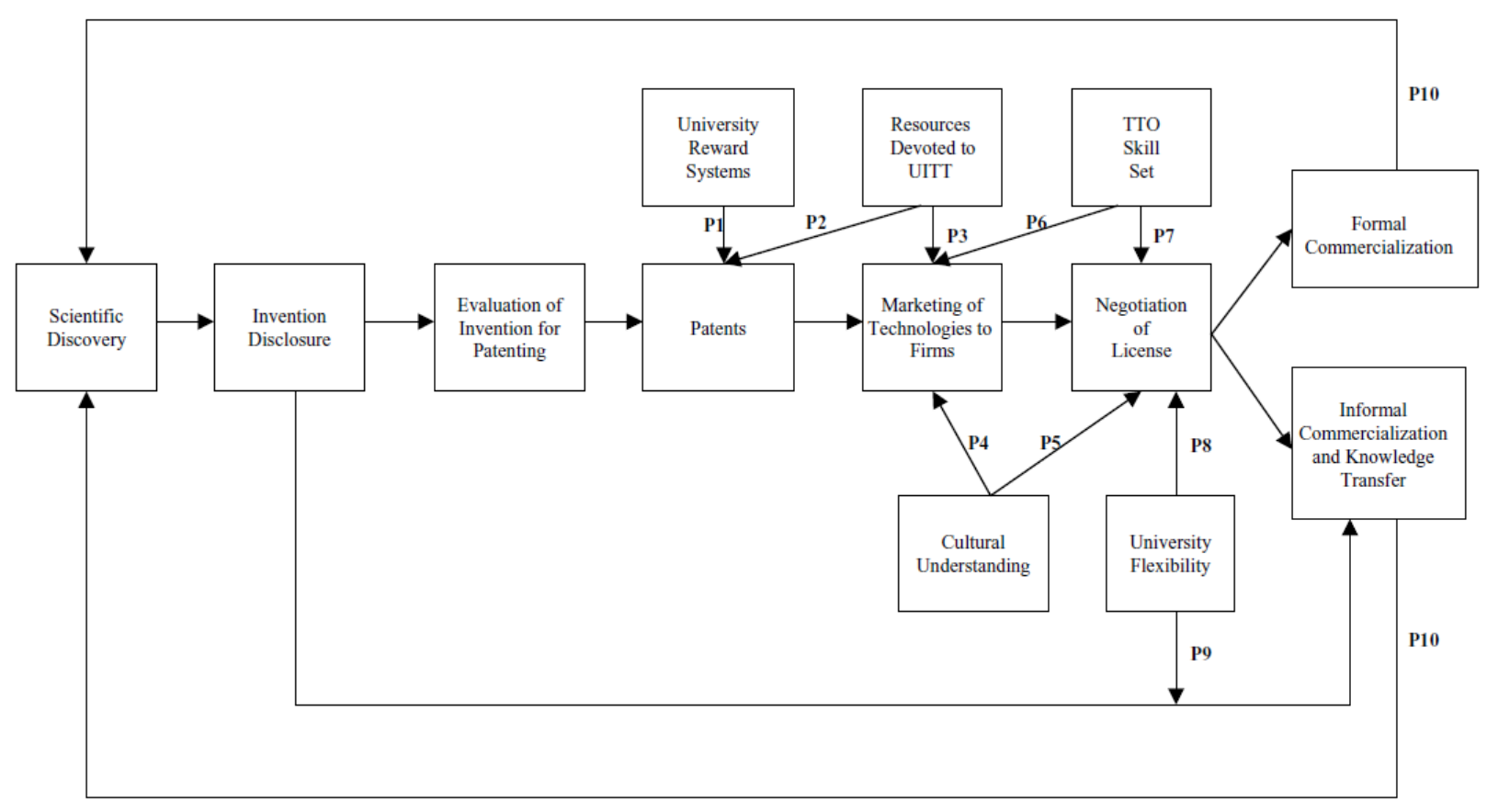

Figure $2 \quad$ Siegel et al. (2004), page 138

\section{Commercial output measurements}

A formalized approach is needed to better harness the potential of inventions (otherwise known as 'technology’) developed by faculty. To address this, dedicated commercialization offices or Technology Transfer Offices (TTOs) have been and continue to be established by universities to support research development and utilization. Concerns of under-utilization of these inventions 
due to an understanding that the private sector would not be interested in their ideas without a way to have any rights to them fueled establishment of the first TTOs (Thursby and Kemp, 2002). These offices were established as early as the beginning of the $20^{\text {th }}$ century. The University of California-Berkley was one of the pioneers to set up a dedicated commercialization driven office in 1912 and other universities such as Stanford and MIT soon followed (Mowery et al., 2001).

Since the enactment of the American legislation that gave intellectual property ownership rights to universities rather than the federal government that funded the research, a university environment has been fertile to grow commercialization capacities. The boom in the 'third mission' in recent years is in part from the expressed desire by universities to grow their University-Industry Technology Transfer (UITT) and a parallel appetite from the industry for university technology (Thursby and Kemp, 2002).

Beyond the establishment of TTOs, universities have also been increasingly supportive of University Spin-Off firms (USOs) or start-ups with the support of a venture capitalist to further the research and development efforts. The start-ups are usually a separate entity, but maintain support and ties to their parent organization. The changes brought about by the Bayh-Dole Act (1980) encourage faculty, as some have suggested, to commercialize invasions through a startup, rather than licensing patents through the TTO in order to commercialize (Aldridge and Audretsch, 2010). For the purpose of this research, licenses, patents, and start-ups are grouped into one broad category called 'UITT’.

Aldridge and Audretsch (2010) found that researchers that abide by institution-owned policies and wish to patent do so by spinning out from the university and creating their own firm, whereas those that make the decision to instead go through their TTO do so through licensing. 
Besides, the line between patenting/licensing and start-ups is blurry considering that many startups spin out only after patents are received (Rasmussen et al., 2006)

As of 2008, the last point of data available from the Survey of Intellectual Property Commercialization in the Higher Education Sector issued by Statistics Canada, 68 of the 77 universities surveyed (88\%) were engaged in intellectual property management and 56 (73\%) had intellectual property offices. Amongst those 77 universities, there were 327 technology transfer staff employed. The types of intellectual property protected from all institutions surveyed, including university affiliated teaching hospitals between the years of 2004 to 2008 can be seen in Table 1. Types of intellectual property protection engaged in from 2004 to 2008, Table 10-1 (Statistics Canada, 2008), with patent applications filed by far being the most popular method of intellectual property protection. In 2008, 1613 invention disclosures were received amongst the responding institutions, with 820 (51\%) of them receiving intellectual property protection and 524 new licences issued, far beyond the number of patent applications for the year. Between 1999 and 2008, there were 1,242 spin-off companies or start-ups begun, at least 573 of which were at least in part for the direct purposes of commercializing. The rationale for 528 of the start-ups was unknown and the remaining 141 were spun out for research and development purposes (Statistics Canada, 2008) 


\begin{tabular}{ll}
\hline & $\begin{array}{r}\text { Responding } \\
\text { institutions }\end{array}$ \\
\hline Filing of patent applications & number \\
Registration of copyright & 53 \\
Registration for industrial designs, trademarks, official marks or integrated circuit topographies & 28 \\
Filing of applications for plant breeders' rights & 7 \\
Executing non-disclosure or confidentiality agreements & 66 \\
Administration of material transferred agreements inbound & 52 \\
Administration of material transferred agreements outbound & 46 \\
Other & 4 \\
\hline
\end{tabular}

Note(s): Based on the questionnaires received representing 125 responding institutions. Institutions: Educational institutions.

Table $1 \quad$ Types of intellectual property protection engaged in from 2004 to 2008, Table 101 (Statistics Canada, 2008)

Motives for Commercialization

Key stakeholders in the transfer of technology from universities to the private sector

\begin{tabular}{|c|c|c|c|c|}
\hline Stakeholder & Actions & Primary motive(s) & Secondary motive(s) & Organizational culture \\
\hline University scientist & Discovery of new knowledge & $\begin{array}{l}\text { Recognition within the } \\
\text { scientific community- } \\
\text { publications, grants } \\
\text { (especially if untenured) }\end{array}$ & $\begin{array}{l}\text { Financial gain and a desire to } \\
\text { secure additional research } \\
\text { funding (mainly for graduate } \\
\text { students and lab equipment) }\end{array}$ & Scientific \\
\hline $\begin{array}{l}\text { Technology transfer } \\
\text { office }\end{array}$ & $\begin{array}{l}\text { Works with faculty members } \\
\text { and firms/entrepreneurs to } \\
\text { structure deals }\end{array}$ & $\begin{array}{l}\text { Protect and market the } \\
\text { university's intellectual } \\
\text { property }\end{array}$ & $\begin{array}{l}\text { Facilitate technological } \\
\text { diffusion and secure } \\
\text { additional research funding }\end{array}$ & Bureaucratic \\
\hline Firm/entrepreneur & Commercializes new technology & Financial gain & $\begin{array}{l}\text { Maintain control of } \\
\text { proprietary technologies }\end{array}$ & Organic/entrepreneurial \\
\hline
\end{tabular}

Table $2 \quad$ (Siegel et al., 2004)

There are two key motives for commercialization: knowledge translation and revenue generation.

In many circumstances, however, the two are intertwined. For example, the need to have

research results in the form of innovation applied is most often realized by bringing it to market, both generating revenue from sales of product of licencing of the invention as well as getting the invention in the hands of those that can benefit from it. This can be seen in Table 2 (Siegel et al., 2004). 
The archetype of academic research defined by Merton (1957) emphasizes research for the purpose of finding answers to problems formerly unsolved and so the purpose of a researcher is thus to find answers and communicate the results for the benefit of society. Lam (2011) found that academic reputation the contribution of knowledge had significantly more impact on faculty’s decision to pursue commercialization than financial motivations such as personal income. Following the Mertonian school of thought into the modern world results that would benefit society are often in the form of inventions, licensing becomes simply a channel for dissemination of results.

Economic pressures from rising costs and strained federal research funding put pressure on universities to be self-sustainable (Argyres and Liebeskind, 1998; Etzkowitz, 2003), however, patents and licensing do not always result in economic gain (Geuna and Nesta, 2006)

\section{Technology Transfer trends}

Started at the beginning of the 1900s by some universities out of a desire to capitalize on the market potential of the innovation developed, growth of technology transfer initiatives in universities in this area remained pretty stagnant until the 1980s with the big boom, namely in the US and the world that followed.

There have been two key waves of commercialization of scientific knowledge. The first, as described, was kick-started with the introduction of the Bayh-Dole act in the 1980s. The second wave, however, came out of a need for universities to be self-sufficient with increased pressure 
to demonstrate economic benefits of their research initiatives and alternative modes of knowledge transfer (Rasmussen et al., 2006).

The entrepreneurial university was started by MIT in the 1800s, followed nearly a century later by a select few other universities at beginning of the 1900s as a mechanism to transfer findings from new applied fields of learning such as agriculture to independent investors and firms (Etzkowitz, 2004). While this entrepreneurial model was adopted by a select few universities throughout the early stages of the 1900s, the growth in this area remained pretty stagnant until the 1980s with the big boom, namely in the US and the world that followed.

\section{Different approaches for different universities}

Based on the attributes of a university, certain commercialization approaches elicit more UITT than others. For example, characteristics such as age, student population size, faculty size, research revenue amount, and the variety of disciplines within the university have an impact on the approaches that would be the most effective for them. Markman et al. (2008), for instance, conducted a thematic analysis of the existing literature on the topic at the time and developed a taxonomy of modes of commercialization, stating the importance of assessing the different modes because differences in university characteristics require differ commercialization approaches. Weckowska (2015) concluded from a qualitative analysis of the learning-in-practice

in case studies of six UK TTOs, that a predominately hands-on relational approach to enhancing UITT is associated with a higher number of licensing deals than a predominately transactional approach, although both are valuable in different respects. 
Following Etzkowitz’s (2001) and Rasmussen \& Borch conviction of universities as entrepreneurial organizations, it is clear that the level and type of support to promote entrepreneurship varies throughout the start-up process. The process begins with informal mechanisms and evolves into organization mechanisms such as a spin-off organization from the university, and then accessing resourcing from sources other than just the university such as investors, industry, or government (Rasmussen and Borch, 2010).

Friedman and Silberman (2003) conducted an analysis of the factors associated with commercial output (invention disclosures). They used a two-equation recursive system to analyze ten TTO outputs and the effect each of four variables had on them: Incentivizing faculty to participate in technology transfer; proximity of the university to concentrations of high technology firms; a clear university mission in support of technology transfer and the experience of the university's technology transfer office. Their results showed that faculty incentives, geographical relation of institution to technology firms, a clear university mission in support of technology transfer, and the experience of the university's technology transfer office were statistically significant and positive (as expected). Each of the four factors have a significant and positive impact of disclosures on license executed which is determined to be the most key commercialization outcome variable.

Thursby and Kemp (2002) considered five key outputs when assessing commercial activity of research universities: (1) Sponsored research agreements between universities and industry; (2) License agreements which permit the use of university IP by private sector firms; (3) Royalty payments received by universities in exchange for the use of IP; (4) Disclosures by faculty to their central administration of potentially commercializable innovations; and (5) University patent applications. 
Siegel et al. (2004) conducted 55 interviews of 98 UITT stakeholders in five American universities. Interviewees were asked about eight different barriers to UITT and three key areas had enough mention to be statistically significant: (1) an unclear line of communication between TTO personnel, researchers, and industry; TTO staffing practices; and inadequate incentives for faculty involvement in UITT.

Research collaborations between academics and firms may increase UITT in the form of patents with an increase in industry funding from 1970-1994 playing a part, although may not be a significant factor in driving the patent generation as they are less correlated with an increase in patent numbers than the influx of US federal grants, disclosure rates and the size of the TTO (Henderson, Jaffe, \& Trajtenberg, 1998).

A 2008 Statistics Canada Survey concluded that universities typically commercialize technology through one of two ways: the technology is either patented or licences to a third party firm; or a new firm is spun out from the university (Statistics Canada, 2008). This survey seems pretty consistent with the rest of the literature and are the key metrics used for assessing UITT activity levels. Bercovitz and Feldman (2006), for example, also used patents, licenses to industry, and start-ups to measure technology transfer impact. The Organisation for Economic Co-operation and Development (OECD) highlighted the challenges of measuring UITT based of off patents and licensing, citing that it diminishes the important of other commercialization channels and called for a reformed way of quantifying such outputs (OECD, 2013).

Thursby and Kemp (2002) found that smaller universities are more similar to larger ones in commercialization approaches than mid-sized institutions. 
In much of the literature on the topic, it was discovered that the incentives provided by the university to their scientists are a likely predictor of UITT efficiency. There is a generally accepted notion that faculty typically don't partake in technology transfer activities for primarily economic motives, but rather to further their career and fulfil a sense of inquiry. While comparing knowledge contribution, reputational, and personal income motivations for commercial engagement, it was found that the financial motivations played the smallest part in motivating faculty by far in comparison to the other two which tested pretty similarly (Lam, 2011). It is for this reason that a number of universities pursue financial and other motivational approaches to encourage faculty to engage in these activities (Anderson et al., 2007; Friedman and Silberman, 2003; Siegel et al., 2004). However, even when properly incentivised, a willingness from faculty to engage in such activities was not found by Geuna and Nesta (2006) to be a significant predictor of UITT since their skills set was developed to excel at publishing which requires different skills and reduces their ability to effectively engage in commercial activity.

It seems that faculty need to be properly incentivised, but that direct monetary compensation is not necessarily the right avenue to stimulate innovation within the university. Thus Siegel et al. (2007) suggests that a favourable intellectual ownership property policies may go a long way to combine the desire for academic fulfillment and the potential for financial gain as part of a healthy and efficient innovation ecosystem. Bercovitz and Feldman (2006) found that institutions with inventor (or creator) owned patentable intellectual property ownership policies were more likely to generate UITT than those that do not. 


\section{Institutional policies}

Rasmussen et al. (2006) observed that universities with institution-owned IP policies may be sorely disappointed if they do not also design a sufficient commercialization framework.

Before the Bayh-Dole Act (1980), universities were not entitled to own intellectual property created by their researchers or which resulted from research funded by the Federal Government, leaving little incentive for universities to pursue this path. In the years since the Bayh-Dole Act, UITT was catalyzed first in the US, followed by universities worldwide that have been increasingly adopting internal policies referencing commercialization mandates and objectives (Aldridge and Audretsch, 2010; Henderson et al., 1998). For instance, the Association of University Technology Managers (AUTM) reported that there were only 25 TTOs established before 1980, but by 1990, 200 were created (Mowery et al., 2001). In another instance, Castillo et al. (2000) found that nearly 4/5 TTOs surveyed were created after the passage of the BayhDole Act.

Such policies do therefore impact the UITT happening at the institution level. Baldini et al. (2006) concluded that universities with internal intellectual property policies have increased commercialization rates by nearly three times as much as they did before the policies. There is also a bandwagon effect associated with the adoption of such policies as each university that creates internal patent regulations sees a 9\% increase in the likelihood that an institution without one will adopt such policies.

After reviewing university polices and organizational structures in the US to support commercialization of university biotechnology research in the decade leading up to 1996, 
Argyres and Liebeskind (1998) conclude that university policies enacted to support commercialization have a significant impact on intellectual property right negotiations and the breadth of support available to increase UITT. The absence of such support mechanisms may inadvertently lead to the creation of new organizations or collaborations fully outside the walls of the institution as a result of no other options available for researchers to expand on their R\&D.

Etzkowitz (2003) rejected the premise that entrepreneurs are created by their cultures, demonstrating that regardless of the present culture, entrepreneurship is an embedded characteristic in academic institutions, whether or not there is a culture to support. People can be trained as entrepreneurs when provided with the right tools. While some may not be able to reach their entrepreneurial potential alone, a culture encouraging collective entrepreneurship will stimulate commercialization. This can be done through enacting enabling policies. Academic institutions have the capability to generate UITT according to a predictable metric. While university policies that encourage commercialization may work there are also concerns that they are met with an equal decline in government support as policies to self-support are implemented (Geuna and Nesta, 2006).

\section{Commercialization offices}

There has been research that indicates that the presence of a TTO, its size, and the capabilities of its staff all affect UITT in a significant way. Ambos et al. (2008) for example concluded that when compared against the level of commercial outputs (patents/licenses and start-ups), the establishment of a TTO showed a positive and significant coefficient, confirming their hypothesis that research projects taking place at a university with a dedicated TTO have a higher likelihood of a commercial output. Boehm and Hogan (2014), however, believe that researchers 
are better situated that TTOs to build the bridges between academia and industry that forge commercial endeavors.

There is also a significant amount of literature supporting a frequent barrier to increasing UITT is insufficient TTO resources- namely not enough trained personnel in terms of appropriate employees skill level and number of staff. For instance, Swamidass and Vulasa (2009) claim that an insufficient number of skilled TTO personnel is the key bottle neck in the university commercialization system, with $68 \%$ of TTOs without a budget to cover their personnel needs or retain staff with an advanced degree in a science or engineering discipline as well as comparable degree in business or law as being a pre-requisite to adequately do the job. They conclude that only about $10 \%$ of universities in the US are thus actually able to benefit from the Bayh-Dole Act. Macho-Stadler et al., (2007) came to a similar conclusion, finding that most universities are unable to drive profit from their intellectual property, even with the establishment of a TTO. Further, they found that TTO staff size has no effect on the number of licences issued, but does have increasing return to scale of revenue from licences. Technology transfer personnel serve a crucial role bridging the vastly different worlds of industry and university academics, bringing together the 'customers' (firms) and ‘suppliers' (university faculty) (Markman et al., 2008). It is for this reason that TTO staffing practices such as hiring and retention of skilled technology transfer officers and faculty incentive programs are quoted as two of the most important factors in UITT success. For instance, Siegel et al. (2003) notes that the measure of skills of TTO personnel is difficult to assess, but suggestions for future variables to example may include the number of start-ups and researcher agreements from UITT. 


\section{Role of the TTO in industry collaborations}

Macho-Stadler et al. (2007) developed a theoretical model that helped demonstrate the catalyzing effects a TTO may have on UITT, by leveraging its experience and reputation with industry. It should be noted here that Macho-Stadler et al. (2007) were referring to income from UITT activity in their study, whereas mine focuses on the number of UITT outputs rather than their value.

Collaborations and ties with industry have been shown to increase UITT. A researcher's embeddedness with industry affects the likeliness of commercial output. For instance, Friedman and Silberman's (2003) results observed a relationship between the geographical proximity of the university to clusters of companies with high technology capabilities and UITT generation.

Commercialization often results from collaboration with industry, whether deliberate or otherwise. Unintended commercial outcomes arise not only directly from the partnership, but also in a show-and-tell manner, giving academics a new perspective on ideas which may be commercially viable and lead to patents, licensing, or a start-ups that they would not have pursued otherwise (Perkmann et al., 2013).

Conversely, Ambos et al. (2008) were surprised not to find evidence that a researcher's embeddedness with industry affects the likeliness of commercial output and offer an explanation that specific experience with a few strong industry relationships may matter more than general experience dealing with the industry. 
Boehm and Hogan (2014) found that the connection between a researcher and industry is essential to the development of a successful commercialization model. They also found that TTOs are negatively perceived by industry and may in fact hurt UITT relationships.

Considering the impact that building a relationship with industry has, Macho-Stadler et al. (2007) stress the significance of building research capacity through a TTO and leveraging the resources and reputation that the university has as a whole that an individual lab or researcher may struggle to achieve. This practice, however, while likely to lead to more valuable innovation and more income as a result, is understood by the authors to produce a lower quantity of UITT outputs due to some projects being "shelved" to preserve the university's reputation.

The University Alliance of England and Wales produced a report on managing IP and technology transfer that notes that it is rare for technology transfer to be managed centrally through a traditional TTO and that a more integrated approach is used to foster strong relationships with industry and ultimately improve UITT (University Alliance, 2016).

\section{Underdeveloped research}

Unfortunately, there has not been much research done in Canada on best practices to support commercialization goals of universities, although there has been a significant amount of research in the US on the impact that the Bayh-Dole Act (1980) has had on university commercialization as well as some research on the emergence of UITT-focused initiatives.

Canadian Universities have been slow to develop infrastructure to support commercialization and what infrastructure does exist only began in the 80s, long after similar developments began 
in the US. According to Statistics Canada, 22\% of Canadian universities did not have a centralized commercialization office by 2008 and $12 \%$ were not even engaged in intellectual property management (Statistics Canada, 2008). According to an AUTM survey, Canadian Universities have fallen behind American ones in terms of technology transfer capabilities, poste Bayh Dole Act because of the Bayh-Dole Act because of a lack of similar federal policy.

Anderson et al. (2007) identifies the size of the TTO in terms of staff, the impact of intellectual property policies, and the systems to incentive researchers as characteristics that are in need of examination. The authors additionally identify a gap in diversity of the origins of research in this field with the vast majority of it coming out of the US. They estimate that there would be similarities amongst the US and Canada, but that research focused on Canada would provide valuable insight into the country's technological strengths. 


\section{Methodology}

As commercialization becomes more embedded in the mandates of universities, it is becoming more important to identify resources to best support faculty and their UITT endeavours. At its core, this is the reason for this study. The study evaluates the impact that Technology Transfer Offices have on commercial outputs (UITT). Similar questions have been explored in the past (Swamidass and Vulasa, 2009), but with different considerations. Swamidass and Vulasa's study used a number of regression models based off 2006 AUTM licencing survey data to assess the capacity of TTO personnel to commercialize technologies, and the effect of the TTO personnel's capacity on key performance measures (Provisional Applications Filed, Patents filed [nonprovisional], Applications and Licenses Executed, and Inventions Not Processed due to staff/budget shortages). Powers (2003) investigated the effects of a set of internal and external resource factors on particular technology transfer outputs.

The statistical analysis of this study was done in three stages. The first stage was descriptive statistics, the second stage examined the differences in both inputs and outputs of universities based on their size using t-tests, and the third stage was completed using multiple linear regression to determine connections between university inputs and UITT outputs.

\section{Variables}

Dependent Variables: $\quad$ Description:

1. Liciss licences issued

2. newpatappfld new patent applications filed

3. stupsformed new start-ups formed 
4. invdisrec

Independent variables:

1. fte_lic

2. fte_others

3. age_office

4. ippolicy

Description:

staff dedicated to licencing

TTO staff dedicated to activity other than licencing

age of the TTO

whether or not there is a creator-owned policy of patentable

intellectual property

Control variable:

1. FTE faculty

2. dollar_per_fac number of full-time or equivalent faculty members

constructed by two other variables - average research revenue

per faculty member, calculated as research expenditure/FTE

faculty (RE\$EARCH Infosource and AUTM licencing survey)

A full list of the variables used, their source, and a description is included in Table 3.

\begin{tabular}{|l|l|l|}
\hline \multicolumn{1}{|c|}{ Variable } & Source & Description \\
\hline age_office & AUTM (TTO established year) & Age of the TTO (calculated as current year- established year) \\
\hline totresexp & AUTM & Annual research expenditure \\
\hline stupsformed & AUTM & Number of spinout companies from faculty as a result of research activity \\
\hline newpatappfld & AUTM & New patent applications filed as a result of faculty research activity \\
\hline liciss & AUTM & Licences issues as a result of faculty research activity \\
\hline FTEFaculty & Research Infosource & Full time or equivilent faculty members \\
\hline fte_others & AUTM & Full time or equivilent staff in a commercialization office dedicated to licencing activity \\
\hline totpatappfld & AUTM & Total number of patent applications filed as a result of faculty research activity \\
\hline licperfac & Combination & Number of licences per faculty member \\
\hline fte_lic & AUTM & Full time or equivilent staff in a commercialization office dedicated to activities other than licencing \\
\hline Research_doll & Research Infosource & Annual research revenue \\
\hline dollar_per_fac & Research Infosource & Research revenue divided by FTE Faculty \\
\hline IP_creator_own & Institutional policies & Determiniation if the insitution has a creator owned policy or not \\
\hline Table 3 & Variable desCriptions \\
\hline
\end{tabular}




\section{Hypotheses}

The top 15 universities in terms of size in any given year (U15), for example, typically have a higher dollar per faculty member value than medium ones, providing some indication that values can be expected to be higher in larger universities simply by virtue of them being larger. This effect is further compounded when considering that all of the U15 universities having TTOs 28 or more years old (established 1990 at the latest). It is thus expected that experience (age) of a TTO and research revenue are positively correlated and more importantly, that large universities have higher UITT than medium or small ones, all else being equal.

Size of the university for the purposes of this study is defined by average annual research revenue received, which is a standard measurement for institutional research intensity rather than the total number of students or faculty members. The 15 universities with the most research revenue are referred to as U15. U15 is a formal collective made up of Canada's leading researchintensive universities which has typically been the 15 largest universities, but in recent years, the University of Guelph has floated in and out of the top 15 (alternating with the Dalhousie University for the $15^{\text {th }} / 16^{\text {th }}$ spot), but is not an official U15 member. For this study, Guelph was considered U15.

\begin{tabular}{|l|l|l|l|l|l|l|}
\hline & $\begin{array}{l}\text { Research } \\
\text { Revenue }\end{array}$ & $\begin{array}{l}\text { Research } \\
\text { revenue } \\
\text { per faculty } \\
\text { member }\end{array}$ & $\begin{array}{l}\text { TTO } \\
\text { Age }\end{array}$ & FTE Lic & FTE other & $\begin{array}{l}\text { Creator } \\
\text { owned IP } \\
\text { policy }\end{array}$ \\
\hline $\begin{array}{l}\text { New patent } \\
\text { applications }\end{array}$ & + & + & + & + & + & $+/-$ \\
\hline Licences & + & + & + & + & + & + \\
\hline Start-ups & + & + & + & + & + & + \\
\hline $\begin{array}{l}\text { Invention } \\
\text { Disclosures }\end{array}$ & + & + & + & + & + & - \\
\hline
\end{tabular}

Table $4 \quad$ Correlations predicted between research intensity and UITT output 
Based on the literature review, the following hypotheses will be tested:

1. In accordance with Table 4, UITT has a correlation with:

-TTO experience (age of TTO, number of staff)

-Research revenue per full time faculty member

-University policies such as intellectual property ownership

2. The number of commercial outputs both overall and per faculty is positively correlated to the size of the university.

\section{Data}

\section{Data sources}

The data used in this empirical study is based on data collected from three survey instruments. The study was conducted to determine UITT activity in Canadian universities under varying conditions.

The first data set and the data at the core of this study was a licencing survey of Canadian and American research institutions conducted annually by The Association of University Technology Managers (AUTM) for the years 2011-2015, inclusively. The analysis was limited to the five year span to minimize variability in policies, department structures, and other changes that may occur. Regardless, due to temporal effects, the data was considered a panel set. AUTM conducts annual licencing surveys of Canadian and American universities, colleges, hospitals, and other related research centers. During the five year time period, over 200 organizations responded to 
the licencing survey. Of those, 42 were Canadian institutions. 11 non-universities and surveys that were not representative of the entire technology transfer activities of the institution were removed, with 31 institutions remaining across the five years.

The variables from the AUTM licencing surveys were chosen to be consistent with standard measurements used by technology transfer offices to measure UITT as well as characteristics about the TTO itself such as age and labour resources. Within TTOs, research intensity and growth is typically measured by research revenue and thus size for this study is measured by this variable.

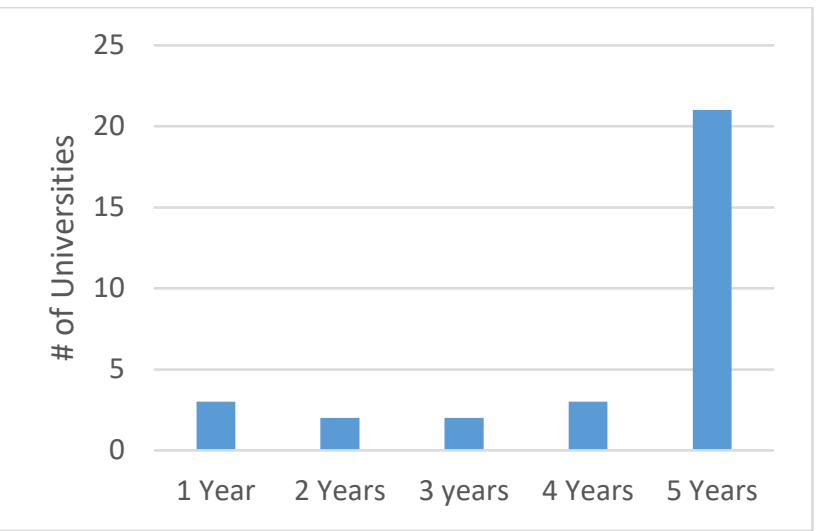

Figure 3 Number of years AUTM survey data is available

The distribution of universities by year:

1. One year: St Francis Xavier University, Wilfrid Laurier University, Mount Saint Vincent University

2. Two years: Lakehead University, Royal Roads University

3. Three years: Ecole De Technologie Superieure, NSCAD University

4. Four years: Queen's University, Saint Mary's University, Laurentian University 


\section{Five years: 21 Universities}

The second data source is a list of the top 50 research universities by sponsored research income for the same time period of 2011-2015 that is published annually by RE\$EARCH Infosource Inc. These top 50 universities are referred to as 'U50'. The AUTM survey data did not include the number of FTE faculty members at each university. This number is important in order to scale other variables such as research revenue and is available through this U50 annual report. This data sheet includes the sponsored research income of each institution from the preceding fiscal year, the number of faculty members, and the average amount of sponsored research income per faculty member. Canadian universities can be thought of as divided into three categories: small, medium, and large. Large ones are the ones in U15 (plus Guelph), medium are those in U50 but not U15 and small is everything else. Since almost all the AUTM licencing survey respondents are also U50 members, for the purposes of this study, all Canadian universities in this study that are not $\mathrm{U} 15$ will be considered medium.

51 Universities made the U50 list across the 5 years. "Canadian University” in the RE\$EARCH Infosource data is a Canadian respondent to the survey that encompasses all UITT activity within the university. Of the 31 Canadian University respondents to the AUTM survey, 26 of which were represented on the U50 list (Royal Roads, Mount Saint Vincent University, Mount Allison University, Lakehead University and NSCAD University were missing).These data were combined with the AUTM survey panel data. University respondents that included data from affiliated hospitals or that were representative only of selective departments/faculties were excluded. Two universities were excluded based on this criteria: McMaster and Western. Not all respondents to the AUTM study, however, had completed the AUTM survey for all of the five years. Additionally, not all Canadian University AUTM licencing survey respondents were 
represented on the U50 list and not all U50 universities took part in the AUTM licencing survey. Therefore some universities were represented in the AUTM data, but not U50 and likewise, some were U50, but did not respond to the AUTM survey. Observations that had data from the AUTM licencing survey but were not represented in U50 were excluded from stage 3 of the analysis.

The third element was a scan of the intellectual property policies of the Canadian university respondents from the AUTM data. While there were 31 university respondents considered from the AUTM licencing survey, due to a French language barrier, I was only able to manually read and analyze intellectual property of the 27 English universities' ownership policies. Policies of the remaining four French institutions (Ecole De Technologie Superieure, Université Laval, University de Sherbrooke, and University de Montreal) were not evaluated.

\section{Variables}

There were multiple observations for each institution over time, with some gaps. Due to the longitudinal nature of the data, a panel data analysis was used to account for temporal effects. The year variable controls for temporal effects. The assumption is that all variables will grow naturally as each university grows, regardless of any changes to the independent variables. Due to this, accounting for the year helps confirm that this standard growth is not the only reason for the UITT growth.

It is assumed that UITT will be correlated with size due to accelerated commercialization resulting from the fact that they have more resources to put into development of UITT. Ambos et al. (2008) ran into a similar challenge when analyzing the stage at which innovations developed by university faculty get commercialized. They tackled this issue by controlling for the duration of the project, FTE staff time spent working on the project and the size of the department. I similarly approached this task by scaling research expenditure by the number of full-time or 
equivalent (FTE) faculty members at each university, a number that was available through RE\$EARCH Infosource.

Three dependent variables were included in this study, all obtained from the 2011-2015 AUTM licensing surveys, each year represented independently and treated as a panel for regression analyses and as average annual measures of commercialization activity for determinations of impact of university size. The three UITT variables are new patent applications, licencing agreements, and start-ups. These three variables represent the three most common channels for realizing innovations through transfer to industry.

With 85\% (28/33) of the AUTM licencing survey respondents also being U50 and all of the U15 members responding, the data seems to suggest that universities with larger research expenditures are more likely to respond the AUTM licencing survey. At the time of this research, there are 96 registered Canadian universities (Universities Canada, 2017). Of the 33 Canadian University respondents, the expectation would be that only 34\% of the U15 would respond if there were no bias towards the U15, but in fact all 16 responded. I predicted that a creator-owned intellectual property policy would increase UITT output since it is assumed that policies that provide benefits for faculty to innovate would result in more innovation from faculty and then more initiatives to commercialize that innovation (UITT).

My study draws on the TTO FTE staff data available from the AUTM licences survey to determine if there is a connection between the number of staff employed to support commercialization of academic research and the UITT generated by the university. The two different staff categories are staff dedicated to licencing and all other staff dedicated to commercialization. 
The main variables used in this study are new patent applications applied for, new start-ups formed, licences issued, FTE TTO staff dedicated to licencing, FTE TTO not dedicated to licencing, and research income per faculty member. There are many other key variables used, however, such as research expenditure, invention disclosures received, FTE faculty, and IP ownership policies. UITT, for the purposes of this study, is the aggregate of new patent applications, licences, and start-ups since each of these activities typically occur at a different stage of the commercialization lifecycle and are unlikely to be double counted. Invention disclosures were not included in the UITT calculation as it is not a commercialization path as the other three are, but more of an input and are not necessarily an accurate representation of commercializable activity and further are likely to be double counted in new patent applications filed since disclosures are typically a result of a requirement from universities policies mandating that faculty do so before applying for patents. Regardless, they do provide some interesting results and although are not including in the variables that make UITT, they were still included in some analyses. Dollar per faculty member can be considered both an independent and a dependent variable, since it is unclear if its value is an outcome of the other independent variables or if it is independent and directly contributes towards UITT activity levels. New patent applications, new start-ups formed, and new licences issued (for each fiscal year), together make up 'UITT output’.

The APLU Report, for example (APLU, 2017), which calls for a focus on economic prosperity rather than revenue as a measure of UITT and a focus on resource allocation such as staffing, is one of the reasons that UITT outputs in this study are measured in number of outputs rather than revenue generated and the staff support available to further UITT. 
The variables new patent applications, licenses issued, and start-ups are extremely important as they represent the number of new innovations ready as they go through the innovation process. Invention disclosure is withheld from the UITT calculations as it is most often done out of obligation, and in reality, only at the time the inventor is ready to proceed with commercialization which would typically occur in the same year as one of the other three measures. The invention disclosure variable represents innovation that the inventor deems has potential for commercialization. Unlike licences executed and patent applications submitted, invention disclosures demonstrates only a willingness to commercialize and do not accurately reflect commercializable potential (OECD, 2013). New patent applications include Canadian patent applications filed by, or with, the assistance of the university's technology transfer office to project faculty-developed innovation during the fiscal year of the reporting year. For this study, it was not possible to separate the patent applications, start-ups, and/or licences that are the result of a single innovation in a single year and thus there is a chance that there are multiple UITT counts for a single innovation in a single year. Start-ups are defined as companies formed with the university's technology transfer office for the purpose of commercializing a faculty member's invention. They are an alternative channel for academics to exploit and commercialize research and development, often when licencing or patenting the innovation to other firms is not an option (OECD, 2013). Licences issued include licence and options agreements executed with companies outside of the scope of the university.

A dummy variable was used to denote whether intellectual property developed by faculty during the course of their academic appointment was owned by them ('creator owned'). Ownership was determined based off of a review of university policies or faculty collective agreements, a 
summary of which can be seen in Table 5. If ownership of patentable inventions is $100 \%$ owned by the inventor then it is considered creator owned ('Yes', ' 1 ') and if ownership is jointly owned between the university and the inventor or solely owned by the institutions then it is considered not creator owned ('no', '0').

\begin{tabular}{|l|l|}
\hline uid & Institution \\
\hline 95099 McGill University \\
\hline 95140 Queen's University \\
\hline 95159 Simon Fraser University \\
\hline 95184 University of Alberta \\
\hline 95187 University of British Columbia \\
\hline 95199 University of Guelph \\
\hline 95209 University of Manitoba \\
\hline 95254 University of Toronto \\
\hline 95261 University of Waterloo \\
\hline 95267 University of Calgary \\
\hline 96014 Lakehead University \\
\hline 96019 Dalhousie University \\
\hline 96034 University of Ottawa \\
\hline 97000 University of Victoria \\
\hline 97009 Ryerson University \\
\hline 97022 University of Saskatchewan \\
\hline 99017 University of New Brunswick \\
\hline 20000027 Memorial University of Newfoundland \\
\hline 20000238 Saint Mary's University \\
\hline 20000239 St Francis Xavier University \\
\hline 20000243 Wilfrid Laurier Univ \\
\hline 20000244 York University \\
\hline 20000012 Laurentian University \\
\hline 20090269 NSCAD \\
\hline 20000234 Mount Allison University \\
\hline 20000237 Royal Roads University \\
\hline 20000235 Mount Saint Vincent \\
\hline
\end{tabular}

\begin{tabular}{|c|c|}
\hline Creator owned? & Source \\
\hline No & S. 5.1: https://www.mcgill.ca/research/files/research/policy_on_inventions_and_software.pdf \\
\hline Yes & 5.1 \& 5.2: http://www.queensu.ca/secretariat/policies/senate/intellectual-property\#principles \\
\hline Yes & 5.1 \& http://www.sfu.ca/policies/gazette/research/r30-03.html \\
\hline Yes & Appendix C,s.3 pg. 67: http://www.hrs.ualberta.ca/MyEmployment/ /media/hrs/MyEmployment/Agreements/Academic/Faculty.pdf \\
\hline No & S. 5.5: https://universitycounsel.ubc.ca/files/2015/03/policy88. pdf \\
\hline Yes & https://www.uoguelph.ca/research/for-researchers/patenting-commercialization/ip-policy \\
\hline No & 2.5(d): http://umanitoba.ca/admin/governance/media/Research_Agreements_Policy__2014_02_03_RF.pdf \\
\hline No & s. $3.1 \mathrm{http}: / /$ www.research.utoronto.ca/industry-and-partners/commercialization-at-u-of-t/ \\
\hline Yes & 3(a): https://uwaterloo.ca/secretariat/policies-procedures-guidelines/policy-73-intellectual-property-rights \\
\hline Yes & 4.12 http://www.ucalgary.ca/policies/files/policies/Intellectual\%20Property\%20Policy.pdf \\
\hline Yes & 6.2: https://www.lakeheadu.ca/faculty-and-staff/policies/research/intellectual-property \\
\hline Yes & S. 23.15: https://cdn.dal.ca/content/dam/dalhousie/pdf/dept/hr/Academic-Staff-Relations/DFA-collective-agreement.pdf \\
\hline No & 5.1: https://www.uottawa.ca/administration-and-governance/policy-29-invention-and-technology-transfer \\
\hline Yes & s. 3 \& 4: https://www.uvic.ca/universitysecretary/assets/docs/policies/GV0215_1180_.pdf \\
\hline Yes & S. 10(d)3: https://www.ryerson.ca/content/dam/faculty-affairs/rfa-collective-agreement/RFA_CA_2015_to_2018.pdf \\
\hline Yes & S. 25.2: http://www.usaskfaculty.ca/wp-content/uploads/2015/06/2014-2017-Collective-Agreement.pdf \\
\hline Yes & S. 38.03: http://www.unb.ca/hr/_resources/pdf/ftaunbtca2013-16.pdf \\
\hline No & Appenix A- A2: https://www.mun.ca/policy/site/policy.php?id=143 \\
\hline Yes & 2.1.1: https://www.stmarytx.edu/policies/wp-content/uploads/2016/10/2017-10-intellectual-property.pdf \\
\hline Yes & 5.2: https://sites.stfx.ca/hr/sites/sites.stfx.ca.hr/files/STFXAUT\%20Collective\%20Agreement\%202016\%20to\%202019\%20Signed.pdf \\
\hline Yes & 36.2.1: http://www.wlufa.ca/wp-content/uploads/2014/06/Wilfrid_Laurier_University_Faculty_Association_2014-2017_Full_time-with-signatures.pdf \\
\hline No & 12.8.: https://www.york.ac.uk/staff/research/external-funding/ip/policy/ \\
\hline Yes & 6.30: https://laurentian.ca/assets/files/CareersLU/LUFA\%20Collective\%20Agreement\%20(2014-17)\%20.pdf \\
\hline Yes & 27.12: http://funscad.ca/wp-content/uploads/2013/Unit\%201\%20CA\%20Jan\%201,\%202013\%20to\%20Dec\%2031,\%202015-1.pdf \\
\hline Yes & 32.01: http://www.mafa.ca/wp-content/uploads/2014/11/MAFA_FT-Collective-Agreement-2016_2019_Final.pdf \\
\hline Yes & 5.2: http://policies.royalroads.ca/policies/intellectual-property-policy \\
\hline Yes & 27.5: http://www.msvu.ca/site/media/msvu/2015-2018\%20MSVUFA\%20FINAL.PDF \\
\hline
\end{tabular}

Table $5 \quad$ Ownership of patentable intellectual property policies

The universities included in the sample generated 1,186 licences, 7,125 invention disclosures, 3,751 new patent applications, and 306 start-ups during the time period, although it is important to note that it is likely that many of the inventions turned into patent applications and further into licences and/or start-ups.

The number of combined UITT outputs (licencing agreements issues, patent applications filed, new start-ups) was 993 in 2011, 997 in 2012, 1,008 in 2013, 1,091 in 2014, and 1,154 in 2015.

\begin{tabular}{rrrrrr}
\multicolumn{2}{c}{} & liciss & newpatents & startups & \multicolumn{2}{l}{ sum } & \multicolumn{2}{l}{ observations } \\
2011 & 238 & 692 & 63 & $\mathbf{9 9 3}$ & 28 \\
2012 & 242 & 709 & 46 & $\mathbf{9 9 7}$ & 27 \\
2013 & 211 & 745 & 52 & $\mathbf{1 0 0 8}$ & 25
\end{tabular}


$\begin{array}{llllll}2014 & 230 & 789 & 72 & \mathbf{1 0 9 1} & 26\end{array}$

$\begin{array}{llllll}2015 & 265 & 816 & 73 & \mathbf{1 1 5 4}\end{array}$

Table $6 \quad$ Number of commercialization observations by year 


\section{Results}

The data were analyzed through univariate, bivariate, and multivariate analyses in that order. The analyses began with descriptive statistics. The means, standard deviations, minimums and maximums were calculated for each variable and each year of the data considered in the study. The results can be seen in Table 7 Summary Statistics. Next, two-tailed t-tests were run for U15 and non-U15 universities within each variable assuming unequal variances using, the results of which are available in Table 8. Each variable was first scaled by number of faculty members, with the exception of dollars per faculty member which was already scaled. Lastly, 17 regression models were run. The results of this stage, including $F$-values, adjusted $R$-squared values, and indicators of significance at the $0.1,0.05$, and 0.001 levels are available in Tables 12-16.

\begin{tabular}{|l|r|r|r|r|r|}
\hline Variable & Mean & Sandard Deviation & Minumum & Maximum \\
\hline lisiss & 9.488 & 10.13 & 0 & 39 \\
\hline resexp & 180.694 & 159.819 & 0.045 & 564 \\
\hline fte_lic & 5.761 & 4.594 & 0 & 20 \\
\hline fte_others & 4.821 & 6.242 & 0 & 33 \\
\hline newpatappfld & 29.77 & 34.603 & 0 & 180 \\
\hline stupsformed & 2.488 & 4.208 & 0 & 23 \\
\hline ippolicy & 0.685 & 0.467 & 0 & 1 \\
\hline & & & & \\
\hline & Number of observations= 850 & & \\
\hline & Summary Statistics & & \\
\hline
\end{tabular}

The AUTM data was the main input for the models developed in this research, however, data from RE\$EARCH Infosource and a scan of AUTM Canadian university responds’ intellectual 
property policy were also included and are available in the appendices. Table 5 shows a short description of the variables used in this research from the AUTM survey.

\begin{tabular}{|c|c|c|c|c|c|c|}
\hline & Totalresexp & liciss & FTE_Lic & TTO_FTE & New patents & startups \\
\hline Average U15 /\#FTE faculty & $\$ \quad 194,811$ & 0.010 & 0.006 & 0.005 & 0.031 & 0.002 \\
\hline Average non-U15 /\#FTE faculty & 72,639 & 0.004 & 0.004 & 0.005 & 0.017 & 0.002 \\
\hline \multirow[t]{2}{*}{ T-test } & 0.000 & 0.007 & 0.154 & 0.947 & 0.082 & 0.893 \\
\hline & Number & & & & & \\
\hline Creator owned U15 & 7 & & & & & \\
\hline Not creator owned U15 & 5 & & & & & \\
\hline Creator owned non-U15 & 12 & & & & & \\
\hline Not creator owned non-U15 & 2 & & & & & \\
\hline$\%$ of U15 Creator owned IP & $58 \%$ & & & & & \\
\hline \% non-U15 Creator owned IP & $86 \%$ & & & & & \\
\hline
\end{tabular}

Table $8 \quad$ Averages and T-Tests of data scaled by number of faculty

Stage 1- Descriptive statistics

\begin{tabular}{|l|l|l|l|}
\hline & All universities & U15 & Non-U15 \\
\hline $\begin{array}{l}\text { Average annual } \\
\text { research revenue }\end{array}$ & $\$ 155,675,230$ & $\$ 284,034,207$ & $\$ 43,361,125$ \\
\hline $\begin{array}{l}\text { Average annual } \\
\text { dollar per FTE } \\
\text { faculty }\end{array}$ & $\$ 154,772$ & $\$ 217,481$ & $\$ 87,240$ \\
\hline Average age of TTO & 21.0 & 28.3 & 14.6 \\
\hline $\begin{array}{l}\text { Average number of } \\
\text { FTE licencing staff }\end{array}$ & 4.9 & 8.9 & 1.5 \\
\hline $\begin{array}{l}\text { Average number of } \\
\text { FTE other TTO staff }\end{array}$ & 4.1 & 7.0 & 1.5 \\
\hline Licences & 8.1 & 13.5 & 3.4 \\
\hline
\end{tabular}




\begin{tabular}{|l|l|l|l|}
\hline Patents & 25.5 & 48.9 & 5.0 \\
\hline Start-ups & 2.1 & 3.8 & 0.7 \\
\hline
\end{tabular}

Table $9 \quad$ Descriptive Statistics for universities included in analysis

Research revenue: The averages of annual research revenue of the 14 U15 universities in the study amounted to $85 \%$ of the total average research revenue across the five years of survey data as can be seen in Table 10 .

Average annual dollar per faculty member: : Research revenue per faculty member across all universities is quite linear and increases proportionally as the faculty pool size increases, as can be seen in Figure 4.

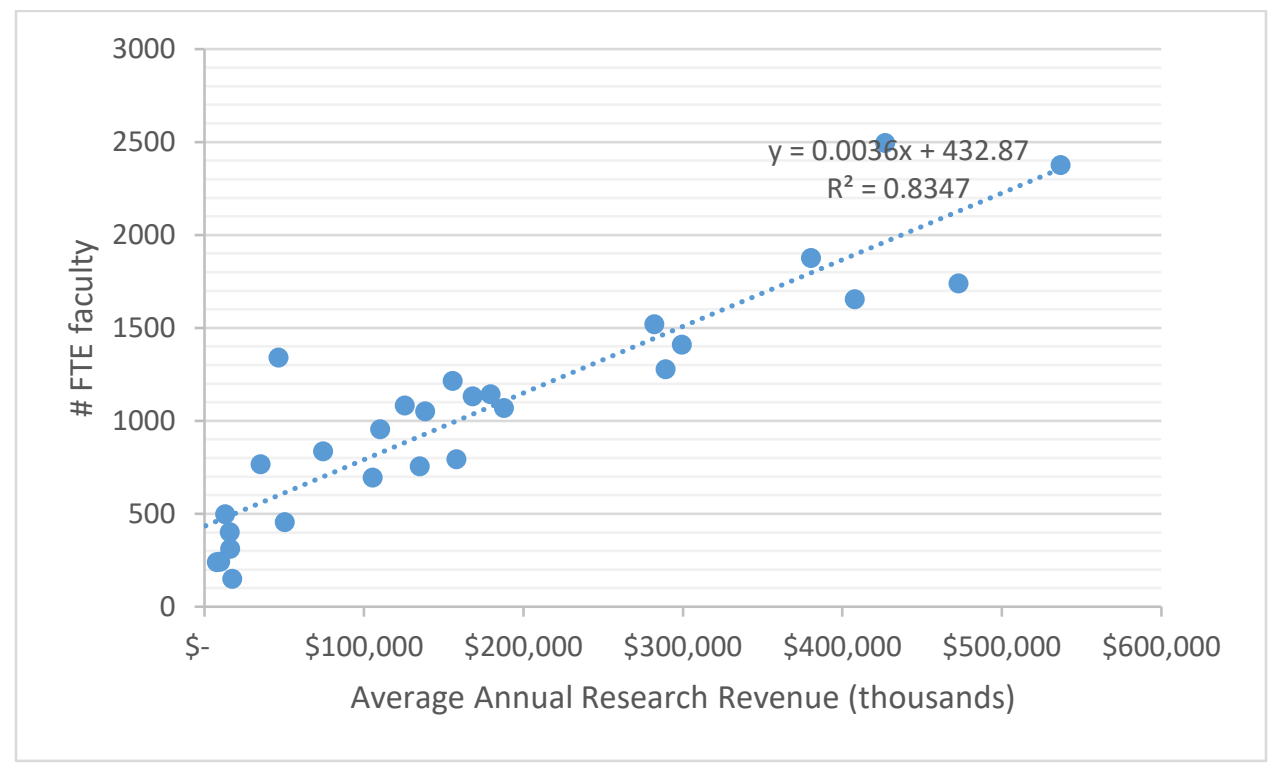

Figure 4 Aggregate research revenue per faculty member for each university

Age: All U15 universities had TTOs established between 1980 (the University of Toronto) and 1990 (McGill University, University de Montreal, University of Waterloo, University of Saskatchewan, and Dalhousie University). Of the remaining 16 universities, 13 had TTOs established 1995 or later. 
Average number of TTO staff: U15 universities averaged 8.5 full time employees dedicated to licencing and 7.2 other staff, whereas non-U15 universities averaged only 1.8 and 1.3, respectively. The number of average TTO staff in the U15 universities include in the study was $83 \%$ of the total average number of TTO staff employed across all the studied universities, as can be seen in Table 10 .

Licences issue: The average number of average new licences issued per year for U15 universities include in the study was $86 \%$ of the total average number of licences issued per year across all the studied universities, as can be seen in Table 10 .

Patent applications: The average number of new patent applications file per year for U15 universities include in the study was $88 \%$ of the total average number of licences issued per year across all the studied universities, as can be seen in Table10.

Start-ups: The number of start-ups developed is by far the most infrequent commercialization channel utilized of the ones studied and primarily only occurs in the largest of the universities. Over half of the total average number of start-ups is from the three universities with the higher dollar per faculty member count as seen in Table 10 and $48 \%$ of the start-ups coming from the University of Toronto.

${ }^{* *}$ The averages were calculated as the sum of the five year averages for the U15 universities divided by the sum of the averages for all universities included in the five years of data included in the study. 


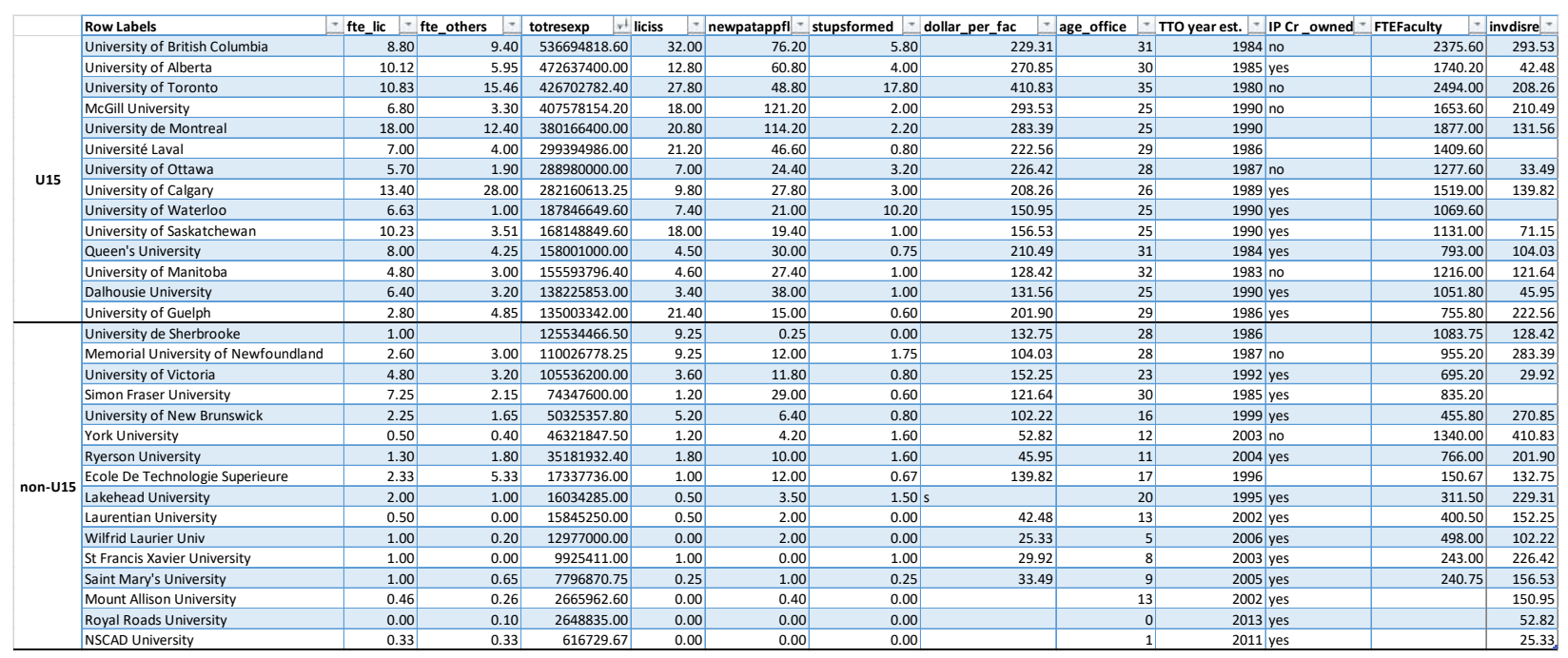

Table 10 Averages across years 2011-2015 by university not scaled by number of faculty

\section{Stage 2- Effects of size; t-tests}

Two-tailed t-tests assuming unequal variances were conducted to determine differences in UITT inputs and outputs of U15 versus non-U15 universities to see if size alone is a factor in generation of UITT. All variables other than dollars/faculty (which were already scaled) have been scaled by the number of FTE faculty members of the university. Only one data point per variable, per institution was used, and was calculated as an average of that variable across all the years that the institution responded to the survey (Table 8).

The average TTO age for U15 universities in 2015 was 27.64, nearly double the average age of non-U15 universities included in the study. Research revenue per FTE faculty member of U15 universities was also significant. Accordingly, U15 TTO offices had more dedicated FTE licencing staff and more TTO staff dedicated to tasks other than licensing per faculty member than did non-U15 institutions in this study.

Based on the t-test results in Table 11, it seems clear that the U15 has an effect that is independent of the number of faculty members. For example, research expenditure $(p=0.000)$, 
patents ( $p=0.082)$, and licencing agreements $(p=0.007)$ are all greater per capita in $\mathrm{U} 15$ universities than in non-U15 universities. The number of start-ups, however, is not significantly higher per capita $(p=0.893)$ in U15 universities. From the t-tests, it is clear that larger universities have more UITT output overall, but the input levels are also higher such as the number of TTO staff. The number of TTO staff per capita, however, is surprisingly not significant in U15 universities.

From these test alone, there is no way to know the reason that the UITT activity levels are higher in larger universities, whether the other factors contribute to the output levels or are simply impacted by the same factors that the UITT levels are affect by and are thus also larger.

The results of the intellectual property ownership policy amongst U15 and non-U15 results seem counter intuitive as U15 universities have mostly non creator-owned policies, but they are also the ones with most UITT per capita. Fifty-eight percent of U15 universities analyzed had creator owned policies, whereas $86 \%$ of the non-U15 universities analyzed in this study were creator owned. 


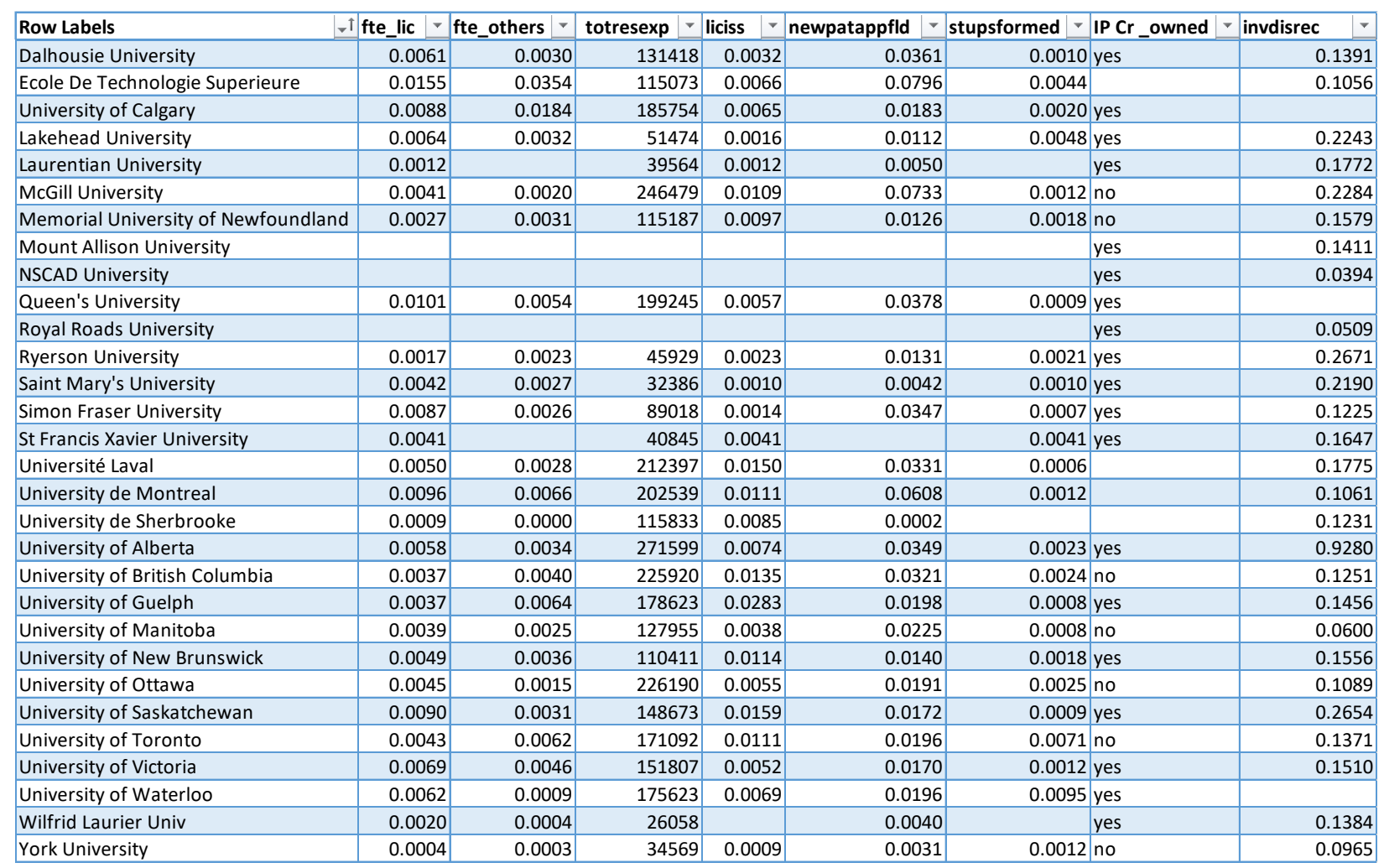

Table 11 Averages across years 2011-2015 scaled by number of faculty 


\section{Stage 3- Regression models}

The study included a number of regression models to estimate the impact of TTO capacity on commercialization variables (i.e., new patent applications file, licenses issues, new start-ups formed) The observations are not inherently 'independent'. To control for the panel nature of the data, the standard errors were clustered based on the respondent ID.

I estimated a series of OLS regression models with clustered standard error. The equation looks like:

$\mathrm{y}=\beta 0+\beta 1 \mathrm{X} 1+\beta 2 \mathrm{X} 2+\beta 3 \mathrm{X} 3 \ldots+\beta \mathrm{XXi}+\mathrm{E}$

There were 129 observations total in the panel data set over the five years. In some instances, however, there is missing data for certain variables and the number of observations is less. For example, there were 126 observations for new patents applications filed, but there were only 124 observations for research expenditure. Over the five years of this study, there were an average of 42 UITT outputs per year, inclusive of 9.49 licences issued per university, 29.77 new patent applications filed, and 2.49 start-ups formed. The data set is heterogeneous with some institutions that did not produce any UITT outputs and some issuing as high as 39, 180, and 23 new licences issued, new patent applications filed, and new start-ups formed, respectively.

From year 2011 to 2015 there is little significant change in any of the variables. Overall, there is a slight upward-downward trend. The average number of licences for example goes from 8.8 to 9.7 to 8.4 to 9.2 and finally to 11.5 in 2015 with an average of 9.5 across the five years. Research expenditure is increasing year-by-year every year all the way up to 2015. New applications filed 
averaged 25.6, 27.3, 29.8, 31.6 and 35.5, averaging 29.8 across the five years. The year was included to account for these temporal effects, but there is not a significant change year over year with one exception. In model 3, the number of TTO dedicated to activities other than licencing did positively impact the number of licences issues (0.067) from 2014 to 2015.
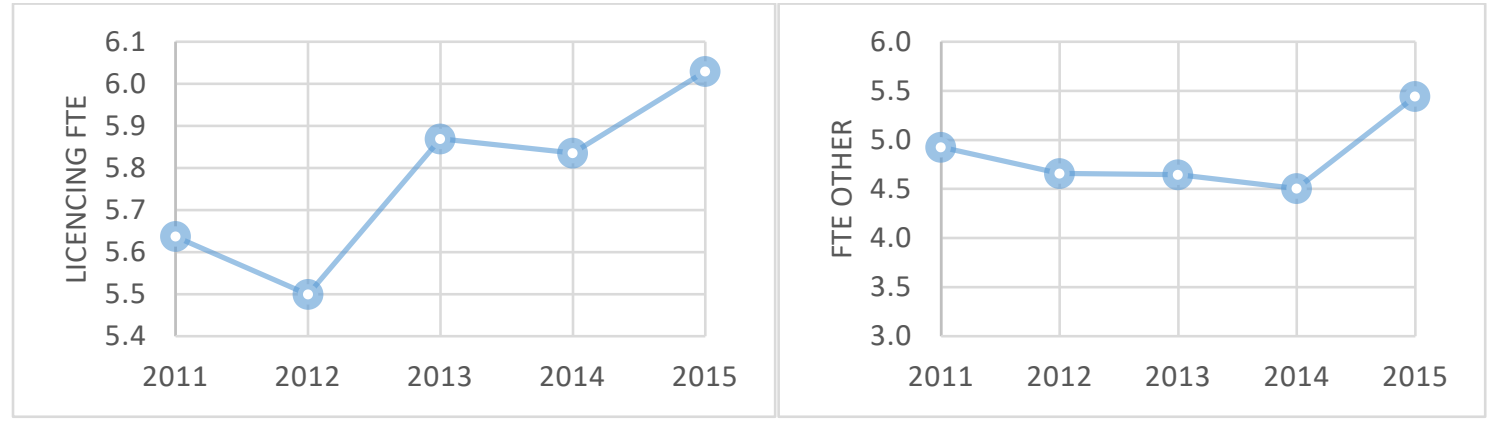

Figure 5

Figure 6
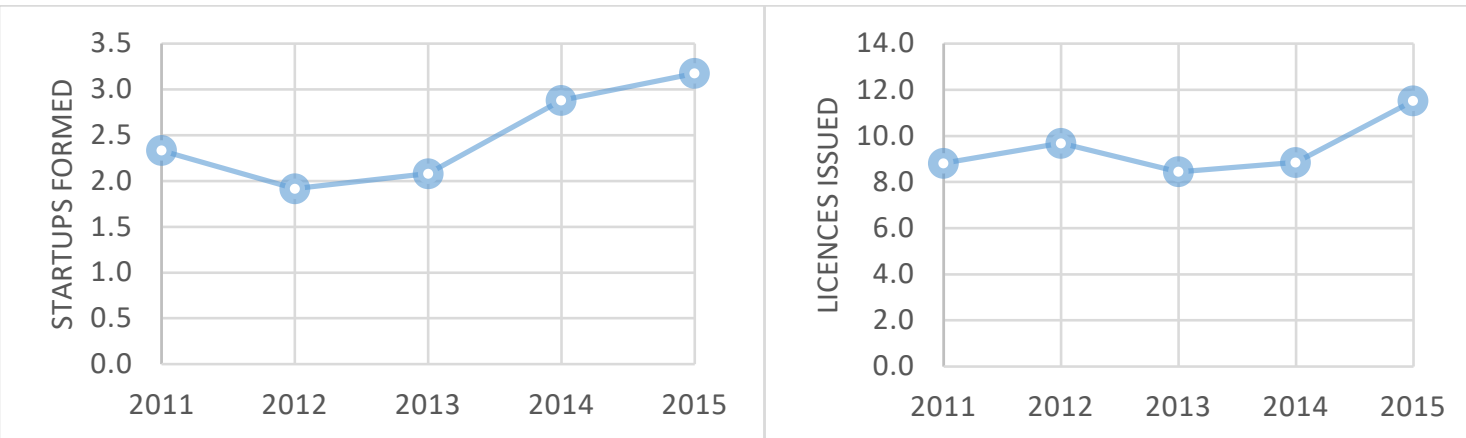

Figure 7

Figure 8
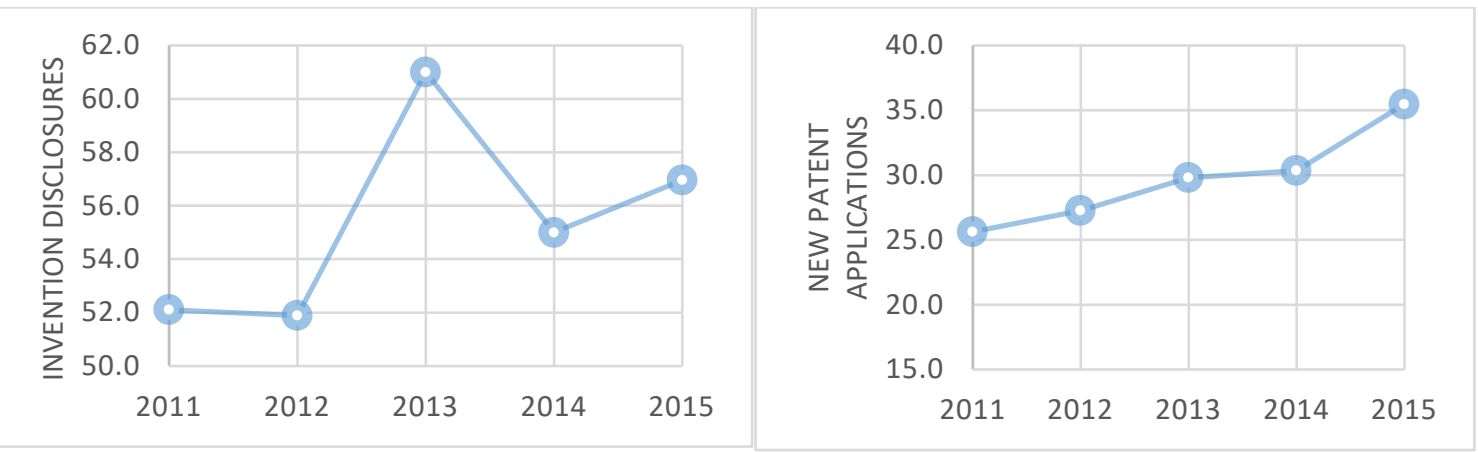

Figure 9

Figure 3 

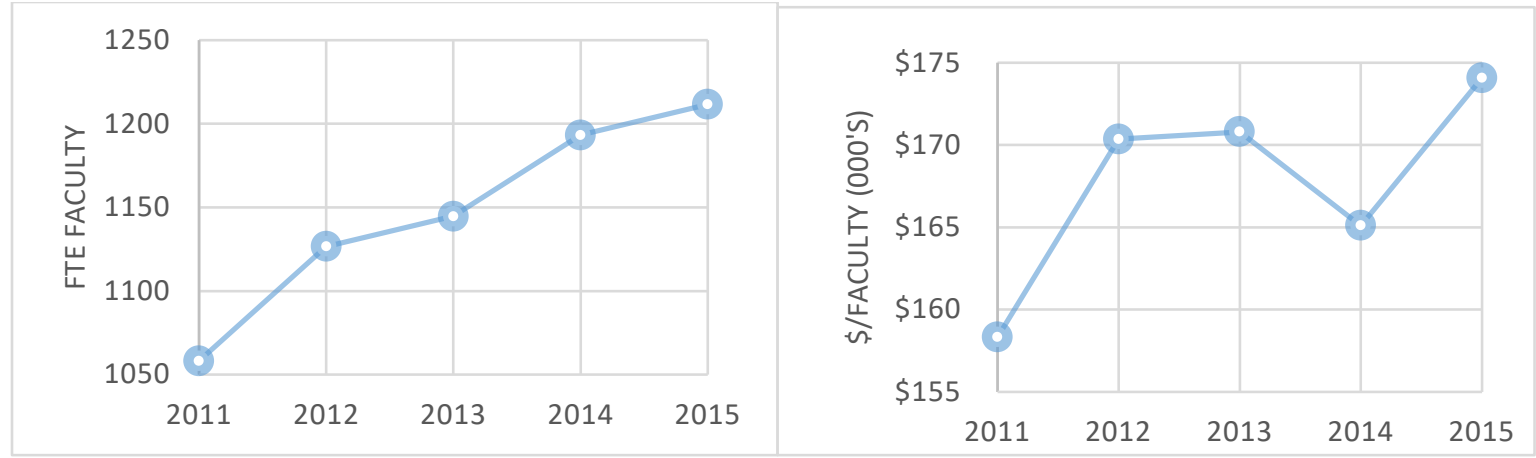

Figure 41

Figure 12

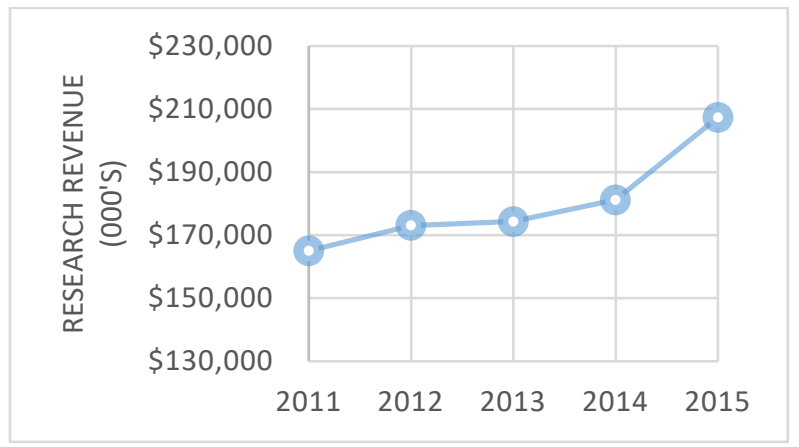

Figure 13 


\section{Regression results}

In regression, the assumption is that all variables are independent of each other. A model evaluation problem I ran into is that not all the independent variables seem to be truly independent of each other and the conclusions drawn from some of models do not appear to be significant in many cases for individual variables, but only when considered as a whole.

Seventeen regression models were run with F-values, adjusted R-squared values, and indicators of significance at the $0.1,0.05$, and 0.01 levels are reported on. The full models explained between 23 and $68 \%$ of the variance in their respective dependent variable and the F-statistic was highly significant in all but one model, the same model with the 23\% R-squared (Model 3).

While the variable for FTE faculty was run, the results do not provide much insight and as expected, the coefficient was positive and significant in every instance.

\begin{tabular}{|c|c|c|c|c|c|c|c|c|}
\hline & $32 \%$ & $30 \%$ & $23 \%$ & $40 \%$ & $38 \%$ & $56 \%$ & $52 \%$ & $30 \%$ \\
\hline liciss & 0.005 & 0.000 & 0.155 & 0.000 & 0.000 & 0.000 & 0.000 & 0.000 \\
\hline variable & Model 1 & Model 2 & Model 3 & Model 4 & Model 5 & Model 6 & Model 7 & Model 8 \\
\hline age_office & $.731(.000)^{* * *}$ & & & $.504(.034)^{* *}$ & $.494(.035)^{* *}$ & $.174(.399)$ & $.059(.771)$ & \\
\hline resexp & & & & & & $.044(.002)^{* * *}$ & & \\
\hline fte_lic & & $1.186(.000)^{* * *}$ & & $.353(.416)$ & $.667(.032)^{* *}$ & $-.114(.765)$ & .005 (.988) & $1.459(.002)^{* * *}$ \\
\hline fte_others & & & $.758(.131)$ & $.323(.468)$ & & & & \\
\hline dollar_per_fac & & & & & & & $.073(.000)^{* * *}$ & \\
\hline ippolicy & & & & & & & & $-4.424(.159)$ \\
\hline
\end{tabular}




\begin{tabular}{|c|c|c|}
\hline & $22 \%$ & $37 \%$ \\
\hline licperfac & 0.038 & 0.000 \\
\hline variable & Model 9 & Model 10 \\
\hline fte_lic & $.000(.448)$ & $.000(.548)$ \\
\hline age_office & $.000(.434)$ & $.000(.240)$ \\
\hline dollar_per_fac & $.000(.088)^{*}$ & $.000(.114)$ \\
\hline ippolicy & & $-.006(.034)^{* *}$ \\
\hline$* p<0.1$ & $* * p<c$ & $.05 ; \quad * * * p<$ \\
\hline
\end{tabular}

Table 13 Regression results of models with Licences Issued per faculty member

\begin{tabular}{|c|c|c|}
\hline & $34 \%$ & $50 \%$ \\
\hline stupsformed & 0.031 & 0.003 \\
\hline variable & Model 11 & Model 12 \\
\hline fte_lic & $-.969(.594)$ & $-.684(.543)$ \\
\hline age_office & $-.453)(.620)$ & $-.142(.143)$ \\
\hline dollar_per_fac & $.031(.094)^{*}$ & $.024(.096)^{*}$ \\
\hline FTEFaculty & & $.003(.012)^{* *}$ \\
\hline ippolicy & & $1.863(.079)^{*}$ \\
\hline
\end{tabular}

Table 14 Regression results of models with Start-ups Formed

\begin{tabular}{|c|c|c|c|}
\hline & $55 \%$ & $40 \%$ & $40 \%$ \\
\hline totpatappfld & 0.000 & 0.000 & 0.001 \\
\hline variable & Model 13 & Model 14 & Model 15 \\
\hline fte_lic & $.994(.300)$ & $2.991(.003)^{* * *}$ & $2.485(.196)$ \\
\hline age_office & $.244(.756)$ & $1.498(.015)^{* *}$ & $1.548(.041)^{* *}$ \\
\hline dollar_per_fac & $.218(.006)^{* * *}$ & & \\
\hline ippolicy & & & $2.982(.813)$ \\
\hline
\end{tabular}

Table 15 Regression results of models with total patent applications filed

\begin{tabular}{|l|r|r|}
\hline & $63 \%$ & $64 \%$ \\
\hline invdisrec & 0.000 & 0.000 \\
\hline variable & Model 16 & Model 17 \\
\hline fte_lic & $-1.128(.630)$ & $-2.900(.366)$ \\
\hline age_office & $.573(.567)$ & $.840(.570)$ \\
\hline dollar_per_fac & $.462(.000)^{* * *}$ & $.428(.005)^{* * *}$ \\
\hline FTEFaculty & $.014(.476)$ \\
\hline ippolicy & $-7362(.582)$ \\
\hline $\begin{array}{l}* p<0.1 ; \\
\text { Table 16 }\end{array}$ & Regression results of models with Licences Issued per faculty member \\
\hline
\end{tabular}




\section{Licences issued (Models 1-8)}

Models 1-8 saw licences issued as the dependent variable. The age of the TTO is significant $(p<$ 0.05) in the number of licences issued in three out of the five models run with the variable, including the model where age of the office was isolated (Models $1,4,5$ ). The number of licencing personnel in the TTO was found to be very significant in isolation (Model 2) although the model fit was only 30\%, but the number of TTO staff dedicated to activity other than licencing was not (Model 3) and the fit was even lower at 23\%, the weakest of all the models run. When these three TTO variables of TTO age, Lice FTE and Other FTE were estimated together (Model 4), only age of the office was significant, but the full model was highly significant $(p=0.000)$ and the model fit saw an improvement at $40.3 \%$. Unsurprisingly, the results demonstrate the value of TTO staff in the licencing process. Opposing my hypothesis, however, is the fact that all other TTO staff are not significant in the generation of licences. From Model 5, it is clear that there is some collinearity between the age of licencing staff and the age of the TTO since why still significant at 0.05 , the number of staff is less significant when the TTO age variable is introduced while the overall mode is highly significant. This corroborates the t-tests in that the larger universities tend to have TTOs established earlier and also have more licencing staff employed. The collinearity is even more distinctive in Model 6, when the research expenditure variable - the variable used to measure university size in this study - is highly significant whereas neither the age of the TTO nor the number of licencing staff are, however, the full model is once again highly significant and the model fit is $56 \%$. The drastic increase in fit and significance of the research expenditure variable is consistent with the results of the t-tests that university size is a key determinate of UITT output. Similarly, the introduction of dollar per 
faculty member in Model 7 is highly significant along with the overall model, but TTO age and number of licencing staff are not.

The number of FTE licencing staff seem to have a direct impact on the number of licences issued in association with an institution, however TTO personnel dedicated to activity other than licences do not. The age of the TTO is significant, but not so when research revenue is considered, either overall or per faculty member. This can perhaps be explained by the fact that most U15 universities are older and so the revenue and age variables cancel each other out. The old universities are the same ones that that have the highest research expenditure amounts and highest dollar per faculty member -Average age of U15 TTO is 28.3, whereas the average age of non U15 UTO is 14.6 and the age of a U15 TTO is significantly different from non-U15 TTOs (refer to T-test chart).

It is difficult to discern the independent effect of TTO staff dedicated to licencing since 13 out of the top 14 universities by number of dedicated licencing staff are U15 universities and also have higher overall UITT activity. For this reason, two models were using the licences per faculty dependent variable.

\section{Licences per faculty member (models 9, 18)}

Scaled by the number of FTE faculty members, none of the research intensity variables, including licences per faculty member, TTO Age, nor dollar per faculty member, seem to have a significant impact on the number of licences per faculty an in-fact, having a creator owned policy has a negative significant impact on the number of licences developed per faculty member. The coefficient is also negative in models for licences not scaled, but not significantly so. In both licences per faculty models run, the research intensity as a whole is significant. Similar to 
licences, none of these variables are significant on their own when dollar per faculty is also included.

The research intensity variables are significant for the most part. The inherent effect of the U15 universities seen in stage 2 of the analysis is demonstrated well here. It seems that the effect of the independent variables are even less predictable when the number of licences issues is scaled by number of faculty members as the fit of the two models was $23 \%$ and $37 \%$, respectively. No independent variables included were found to be highly significant and positive, however, having a creator-owned intellectual property policy had a negative significant $(p>0.05)$ effect and the full model was found to be highly significant. The model that did not include an intellectual property ownership component was significant only at 0.05 . The age of the TTO office and number of FTE TTO staff dedicated to licensing are significant only when licences are not scaled by number of faculty members. It seems clear that a university with a larger and more established TTO office will generate more licences overall than one does not, but research efficiency (licences per faculty member) does not seem to be significantly impacted. These results loosely contradict Macho-Stadler et al.'s (2007) results that TTO staff size does not have an effect on the number of licences issued.

\section{Start-ups formed (models 13, 20)}

Similar to the results for licences issued per faculty member, the amount of research revenue per faculty member is significant at 0.1 while model fit is vastly improved with the introduction of the intellectual property variables. Further, just like the licences issued per faculty models, the introduction of intellectual property ownership increases the significance of the full model ( $p$ $=0.003)$. Unlike licences issued per faculty member, however, the model with dependent variable 
Start-ups Formed that includes creator-owned policy has a positive, albeit mildly significant impact. Dollar per faculty has a significant and positive impact on the number of start-ups formed (at 0.1) in both models run for start-ups formed, but the age of the TTO and the number of FTE licencing staff are both negative, yet insignificant in both models run.

The results seem to indicate that the more research revenue received on average per faculty member has a positive impact on the number of start-ups formed, as does having a creator owned IP policy. The age of the office and the number of licencing support staff, however, seem to be irrelevant. Faculty are more likely to spin out and create their own firm when the intuition holds a creator-owned IP policy. There is a limitation in the data, however, due to the limited number of start-up data points. As noted earlier, over half of the total average number of start-ups is from the three universities with the higher dollar per faculty member count (Table 10 ) and $48 \%$ of the start-ups coming from the University of Toronto. Regardless, it seems that start-ups will be formed or not formed regardless of the support from a TTO. They will be formed equally without its help and in turn, support from the office is no more likely to lead to the generation of start-ups.

\section{Invention disclosures (models 15, 16, 21)}

Invention disclosures are the most predictable of all the dependent variables included. The two models in Table 16 have the highest model fit at 63 and 64\% and a p-value of 0.000 . In both models, dollar per faculty was highly significant and was the only significant variable. Similar to start-ups formed, the number of dedicated licencing staff had a negative, but insignificant coefficient. The effect of having a creator-owned IP policy is also negative, but insignificant.

Invention disclosures are often a formality and typically for the benefit of the TTO. For this reason, fewer disclosures were expected from institutions with a creator-owned policy since a 
disclosure in these institutions would typically only occur only when commercialization was imminent, unless otherwise required by the intuition which is more likely the case in institutions where intellectual proprty is institution-owned (OECD, 2013). The results do not contradict this hypothesis, but also does not strongly support it. Invention disclosures are the only variable tested where the average occurrence per faculty member is no statistically different between U15 and non-U15 universities as can be seen in Table 8. While tracking the number of invention disclosures disclosed to the TTO represents the willingness of the institution's faculty to pursue commercial avenues for their inventions, the stage at which the disclosure occurs is too early stage to truly be indicative of UITT.

\section{Total Patent Applications filed (models 10, 12, 19)}

Not surprisingly, the age of the TTO has a significant effect on the total patent applications filed in models where dollar per faculty is not present to cancel it out. This makes sense since the longer the TTO office has existed, the more patent applications I would expect from it. Having a creator-owned policy is not a significant indicator in the number of patent applications filed. As the dollar per faculty variable can be considered either dependent or independent, models without it may tell a clearer story of the truly significant independent variables. That said, although the model fit decreases without it, the significance of the age of the TTO $(p>0.05)$ is unsurprising that the longer a TTO has been in existence, the more patent applications one could expect to accrue. Unlike the number of new invention disclosures and new start-ups formed, however, the number of dedicated licencing staff is a significant predictor of the total number of patent applications filed in conjunction with a TTO. This is perhaps because of the link that exists between issuing licences and applying for patent applications, both dependent variables in 
which the number of licencing staff in the TTO is important. A further exploration of this linkage could also help explain the insignificance of having a creator-owned intellectual property policy is on either of these dependent variables. It would have been surprising had the presence of a creator-owned intellectual property policy has a significant and positive effect on the number of patent applications filed since it is assumed that institutions which give their faculty the freedom to solely own patentable intellectual property would not necessarily be associated with patent applications filed as a result of academic research. As expected, this result is insignificant. 


\section{Discussion}

Organization size and research intensity

Besides the size of the faculty pool, the research revenue and research revenue per faculty member variables were the only ones that were consistently significant. Similar to the number of faculty members, the impact of research revenue was assumed to have a highly significant influence on the rate of UITT generated. Dollar per faculty member, however, was thought to be more indicative of a recognizable pattern in the data. Unfortunately, the results associated with this variable were inconsistent. This may be because it has the potential to be both an independent and a dependent variable and is masking the effects of other independent variables included in the models, especially since most full models were highly significant. On its own, the research revenue variables divided by the number of faculty members seems have a mostly linear pattern as can be seen in Figure 4. The growth in dollars per faculty seems to grow along with university size. This result is a clear indication that growth in research revenue and the corresponding number of full time faculty members is matched with an equal average growth in research intensity of each individual faculty member. Due to the dual function of the dollar per faculty variable as both a dependent and independent variable, it is difficult to tell if growth of dollars per faculty member is because of or the reason for increases in UITT outputs. Regardless, this variable was significant in all but one model that it was included in. Model 10, the only mode that this variable was not significant in is also the only model with a significant negative coefficient. As predicted, the U15 universities pump out more UITT activity than smaller 
universities. When scaled, however, the number start-up firms are not unduly influenced by the size of the institution.

\section{Human Capital and Organizational experience}

The causation versus correlation conundrum present in the dollar per faculty analysis is not applicable to the licencing staff and other TTO staff variable and as such, instills confidence that these variables are truly independent.

It was hypothesized that the results of the study would reflect an increased level of UITT in larger universities and unsurprisingly, in most cases it did. Powers (2003), for example, noted that universities with more TTO staff would be expected to excel at UITT better than those with smaller offices and further that the UITT generated could be expected to be boosted by universities with older TTOs since they have developed and honed the requisite skill set to manage UITT operations.

The results of the study confirm the estimation that TTO experience and number of dedicated licencing staff benefit UITT, or at least licences issued and total applications filed as is seen in Table 12 and Table 15. These results are consistent with of Ambos et al. (2008) that was discussed in the literature review. They had concluded that the presence of a TTO showed a positive and significant relationship with the levels of patents, licences, and start-ups.

As expected, the results regarding TTO FTE licencing staff do have a noticeable benefit on the number of licences executed however, the number of dedicated technology transfer staff dedicated to licencing or otherwise does not appear to enhance UITT output rates overall. When 
scaled, however, the number of TTO staff per faculty member is not significantly different amongst U15 and non-U15 universities (Table 8).

\section{Policy implications}

The intellectual property ownership variable was significant and positive in one model, but only at 0.1 and significant, but negative in one model at 0.05 . The coefficient was positive in one other model, and negative, but insignificant in the rest. These findings were in conflict with the hypothesis that having a creator owned policy would have a significant and positive effect on UITT. A creator owned policy had a positive, but insignificant coefficient for invention disclosures received and patent applications filed, a positive and significant effect on start-ups formed, but had a negative coefficient for the number of licences and the number of licences per faculty member. Having a creator-owned intellectual property policy has a significant effect in licences per faculty and start-ups formed, but the effect is negative in the first and negative in the latter. The policy therefore has essentially no effect on licences issued overall, but does have a negative effect looking at licences scaled per faculty member at 0.1 .

From the study results, it seems evident that having a creator owned policy did not have the positive significance expected on UITT. In most cases, it was insignificant or even had a negative effect. While this result may seem counter-intuitive, when the intellectual property is inventor-owned, the inventor is more likely to apply for patents and create spin-out companies. Based on these results, it appears that the policies surrounding ownership of patentable intellectual property don't especially seem to help or hurt UITT and may in fact be irrelevant. The UITT numbers under creator-owned policies, however, may be higher since there is 
significantly less incentive to go through the TTO and so the reported numbers would not include technology commercialized outside the walls of the university. An opinion piece by University Affairs expressed similar sentiments claiming that intellectual property policies in Canadian universities discourage academics from creating start-ups to commercialization their inventions and went even further to claim that these spin-out companies are becoming the top channel for commercialization technology (De Baere and Maine, 2017).

From the literature review, it was assumed that institutions with creator owned patentable intellectual property ownership policies were more likely to generate UITT than those that do not. While the intellectual property policy is significant on some UITT activities, based on the data available, the results do not support this conclusion overall. Since the data available in the AUTM licencing surveys is self-reported by the universities, it is very likely that some UITT outputs are not reflected. Were all that information available, the results may be more reflective of the predictions.

\section{Summary}

As expected, the annual research revenue received by a university and the amount of research funding per faculty member was positively correlated with all UITT outputs in nearly all cases. TTO age and the number of licencing staff overall affect the number of patents and licences generated, however, the number of staff dedicated to activity other than licencing was not found to have a significant impact. Further, a creator-owned IP policy does not seem to impact UITT overall in a positive and significant way and appears to almost be a disincentive in some cases, although patents and licencing agreement established outside the scope of the university due to such policies may be responsible for this result. A creator owned policy did have the expected effects on the number of firms spun-out from the university. 
Based on the literature review, a correlation between size (research revenue) and all UITT measurements was suggested that larger universities produce more UITT regardless of other factors, but that the other characteristics would nonetheless impact the amount of technology that gets commercialize. As assumed, the size of the university, measured as research revenue, has the most impact on the amount of UITT generated by a university. While other variables are significant, none maintain their significance with the introduction of research expenditure or dollar per faculty. Additionally, any model with either of these variables in it had a model fit of $50 \%$ or higher.

It is difficult to tease apart which variables are truly independent and which are computed from other variables in the data set. For example, the dollar per faculty member variable may be influencing UITT calculation variables, however, it is unclear if this variable causes the UITT to be higher in U15 institutions as an independent variable or is a dependent variable and is higher in U15 universities because of the same root causes that the other variables are higher. This collinearity presents a challenge in receiving accurate results on the regression models since it seems as though there may be a strong correlation between many of the variables, specifically research expenditure, dollar per faculty, TTO age and number licencing staff. This conclusion does, however, reflect Siegel et al.’s (2004) updated technology transfer model Figure 2. Similarly, in-line with the literature, (such as Siegel et al. 2003), older TTOs tend to generate more licencing agreements than their younger counterparts. 


\section{Conclusions}

This research attempted to assess what institutional characteristics effect commercialization of academic research in Canadian Universities. Overall, the results of the study do not provide much conclusive guidance on the reasons for UITT growth beyond the size of the university, but they do suggest that there is some greater effect of U15 universities that leads to more UITT activity than smaller universities. Nonetheless, this study has provided useful insight through ruling out some internal university factors as the cause and would provide future researcher with a solid baseline understanding of the connectivity amongst seemingly independent influences on technology transfer outputs in Canadian universities.

\section{Limitations}

The largest limitation of the study is the collinearity amongst the seemingly independent variables. A second limitation is incomplete data, namely those universities that responded to the AUTM licencing survey but were not U15 and the French-speaking universities for which a review of the intellectual property policy was not possible.

A third limitation is inaccessibility of commercialization measures outside of those reported by the universities. For example, the patent application data available for this study only included applications issued in consultation with the TTO, however, the survey results do not include those patents applied for independently, but that were still developed through academic research. This it is important to note that since the TTO is not necessarily a touch point, institutions with lower patent applications are not necessarily less effective at UITT generation, but rather that 
they have less of a direct tie to patents coming out of academic research associated with the university.

Lastly, in retrospect, all variables used in the stage three analyses should have been scaled by the number of faculty members based on the results of the t-tests. Further, is not known whether the results are generalizable to non-U50 universities since very few small universities were included, although this would be a good area for future research.

\section{Areas for Future Research}

Future research would benefit from collecting primary data from researchers themselves to have a more accurate sample of commercialization initiatives being taken as a result of academic research being conducted and the true impact of a creator-owned intellectual property policy. Further, a decentralized approach to technology transfer such as the approach used in England and Wales as explained in the literature review may return more tangible results (University Alliance, 2016).

Other factors influencing UITT would be important to include in future research. Other variables could include geographical location of the university; experience and skills possessed of TTO staff; departments/programs of the university. A deeper exploration of behavioural variables that influence an inventor's decision to pursue commercial avenues would also be of great interest. Conducting a survey to collect primary data instead of the using AUTM data received would be beneficial and a good way include smaller universities. 
The literature highlights differences in commercialization approaches needed for each university based on various characteristics, many of which were analysed in this study. Future research could focus on the different approaches available to encourage commercialization and the ones most appropriate for a university depending on its characteristics such as size, age, and existing UITT activity levels. This may include changes to internal policy, hiring practices, or faculty incentives. 


\section{References}

Aldridge, T., and Audretsch, D.B. (2010). Does policy influence the commercialization route? Evidence from National Institutes of Health funded scientists. Res. Policy 39, 583-588.

Ambos, T.C., Mäkelä, K., Birkinshaw, J., and d'Este, P. (2008). When does university research get commercialized? Creating ambidexterity in research institutions. J. Manag. Stud. 45, 14241447.

Anderson, T.R., Daim, T.U., and Lavoie, F.F. (2007). Measuring the efficiency of university technology transfer. Technovation 27, 306-318.

Association of University Technology Managers (AUTM). The AUTM Licensing Survey, 2011, 2012, 2013, 2014, and 2015.

Argyres, N.S., and Liebeskind, J.P. (1998). Privatizing the intellectual commons: Universities and the commercialization of biotechnology. J. Econ. Behav. Organ. 35, 427-454.

Baldini, N., Grimaldi, R., and Sobrero, M. (2006). Institutional changes and the commercialization of academic knowledge: A study of Italian universities' patenting activities between 1965 and 2002. Res. Policy 35, 518-532.

Bayh-Dole Act, 1980, Patent and Trademark Act Amendments, P.L. 96-517.

De Baere, B, and Maine, E. (2017). Canada needs a national overhaul of university IP policies. University Affairs. Retrieved from https://www.universityaffairs.ca/opinion/in-myopinion/canada-needs-national-overhaul-university-ippolicies/?utm_source=Academica+Top+Ten\&utm_campaign=06b8032dfbEMAIL_CAMPAIGN_2017_09_18\&utm_medium=email\&utm_term=0_b4928536cf06b8032dfb-51942205

Bercovitz, J., and Feldman, M. (2006). Entpreprenerial Universities and Technology Transfer: A Conceptual Framework for Understanding Knowledge-Based Economic Development. J. Technol. Transf. 31, 175-188.

Boehm, D.N., and Hogan, T. (2014). 'A jack of all trades': the role of PIs in the establishment and management of collaborative networks in scientific knowledge commercialisation. J. Technol. Transf. 39, 134-149.

Chapple, W., Lockett, A., Siegel, D., and Wright, M. (2005). Assessing the relative performance of U.K. university technology transfer offices: parametric and non-parametric evidence. Res. Policy 34, 369-384.

Cummings, B. (2013). The changing landscape of intellectual property management as a revenue-generating asset for US research universities. Geo Mason Rev 21, 1027. 
Etzkowitz, H. (2003). Research groups as 'quasi-firms': the invention of the entrepreneurial university. Res. Policy 32, 109-121.

Etzkowitz, H. (2004). The evolution of the entrepreneurial university. Int. J. Technol. Glob. 1, 64-77.

Friedman, J., and Silberman, J. (2003). University technology transfer: do incentives, management, and location matter? J. Technol. Transf. 28, 17-30.

Geuna, A., and Nesta, L.J.J. (2006). University patenting and its effects on academic research: The emerging European evidence. Res. Policy 35, 790-807.

Henderson, R., Jaffe, A.B., and Trajtenberg, M. (1998). Universities as a source of commercial technology: a detailed analysis of university patenting, 1965-1988. Rev. Econ. Stat. 80, 119127.

Lam, A. (2011). What motivates academic scientists to engage in research commercialization: 'Gold', 'ribbon' or 'puzzle’? Res. Policy 40, 1354-1368.

Macho-Stadler, I., Pérez-Castrillo, D., and Veugelers, R. (2007). Licensing of university inventions: The role of a technology transfer office. Int. J. Ind. Organ. 25, 483-510.

Markman, G.D., Siegel, D.S., and Wright, M. (2008). Research and technology commercialization. J. Manag. Stud. 45, 1401-1423.

Merton, R.K. (1957). Priorities in Scientific Discovery: A Chapter in the Sociology of Science. Am. Sociol. Rev. 22, 635.

Mowery, D.C., Nelson, R.R., Sampat, B.N., and Ziedonis, A.A. (2001). The growth of patenting and licensing by US universities: an assessment of the effects of the Bayh-Dole act of 1980. Res. Policy 30, 99-119.

OECD (2013). Education at a Glance 2013 (OECD Publishing).

Perkmann, M., Tartari, V., McKelvey, M., Autio, E., Broström, A., D’Este, P., Fini, R., Geuna, A., Grimaldi, R., Hughes, A., et al. (2013). Academic engagement and commercialisation: A review of the literature on university-industry relations. Res. Policy 42, 423-442.

Powers, J.B. (2003). Commercializing Academic Research: Resource Effects on Performance of University Technology Transfer. J. High. Educ. 74, 26-50.

Rasmussen, E., and Borch, O.J. (2010). University capabilities in facilitating entrepreneurship: A longitudinal study of spin-off ventures at mid-range universities. Res. Policy 39, 602-612. 
Rasmussen, E., Moen, Ø., and Gulbrandsen, M. (2006). Initiatives to promote commercialization of university knowledge. Technovation 26, 518-533.

Siegel, D.S., Waldman, D., and Link, A. (2003). Assessing the impact of organizational practices on the relative productivity of university technology transfer offices: an exploratory study. Res. Policy 32, 27-48.

Siegel, D.S., Waldman, D.A., Atwater, L.E., and Link, A.N. (2004). Toward a model of the effective transfer of scientific knowledge from academicians to practitioners: qualitative evidence from the commercialization of university technologies. J. Eng. Technol. Manag. 21, 115-142.

Siegel, D.S., Veugelers, R., and Wright, M. (2007). Technology transfer offices and commercialization of university intellectual property: performance and policy implications. Oxf. Rev. Econ. Policy 23, 640-660.

Sohn, S.Y., and Moon, T.H. (2004). Decision Tree based on data envelopment analysis for effective technology commercialization. Expert Syst. Appl. 26, 279-284.

Swamidass, P.M., and Vulasa, V. (2009). Why university inventions rarely produce income? Bottlenecks in university technology transfer. J. Technol. Transf. 34, 343-363.

Thursby, J.G., and Kemp, S. (2002). Growth and productive efficiency of university intellectual property licensing. Res. Policy 31, 109-124.

Thursby, J.G., Jensen, R., and Thursby, M.C. (2001). Objectives, characteristics and outcomes of university licensing: A survey of major US universities. J. Technol. Transf. 26, 59-72.

Weckowska, D.M. (2015). Learning in university technology transfer offices: transactionsfocused and relations-focused approaches to commercialization of academic research.

Technovation 41-42, 62-74. 